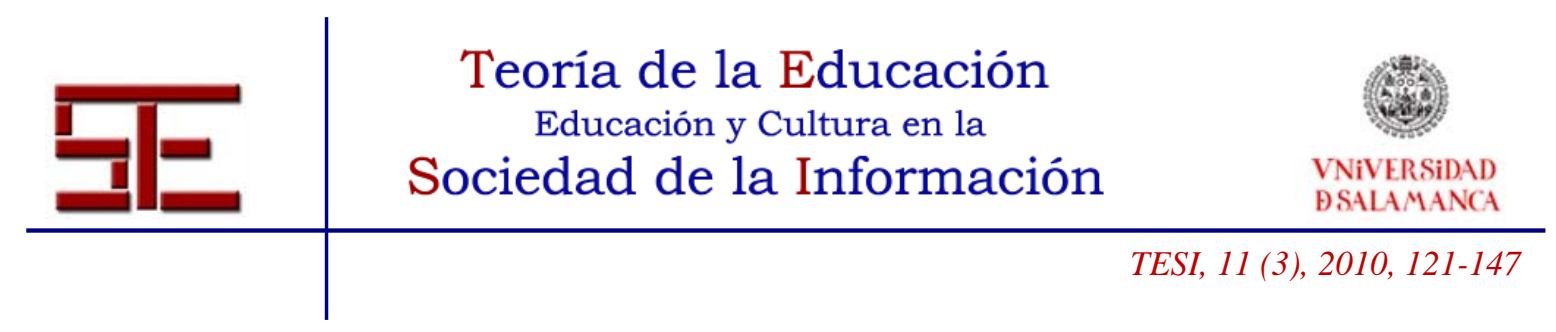

\title{
VARIABLES DOCENTES Y DE CENTRO QUE GENERAN BUENAS PRÁCTICAS CON TIC ${ }^{1}$
}

\section{Resumen:}

En este artículo se presentan los resultados de un estudio de casos llevado a cabo mediante entrevistas narrativas, cuyo objetivo es identificar los factores condicionantes de las buenas prácticas con TIC. Las buenas prácticas con TIC están relacionadas con dos áreas científicas de estudio. Una referida a la integración de las TIC en los sistemas educativos y otra ligada a procesos de innovación. En esta aportación se presenta el estado de la cuestión respecto a factores condicionantes de las buenas prácticas desde ambas perspectivas. A partir de ahí situamos el marco teórico de este trabajo desde la perspectiva del profesorado. El análisis cualitativo realizado mediante el software científico Atlas.Ti 5.0 saca a la luz variables personales y contextuales asociadas a los procesos de innovación.

\section{Palabras clave:}

Innovación, Profesorado, Buenas prácticas, Tecnologías de la Información y la Comunicación TIC, factores condicionantes del uso de las TIC.

\footnotetext{
1 Este estudio forma parte del Proyecto I+D "Políticas educativas y su impacto sobre la innovación pedagógica, apoyada en el uso de las TIC en los centros escolares” (Referencia: SEJ 2006-12435-C0501) subvencionado por el Ministerio de Ciencia y Tecnología destinado a estudiar el impacto de las políticas educativas en prácticas innovadoras con TIC (Tecnologías de la Información y la Comunicación).
}

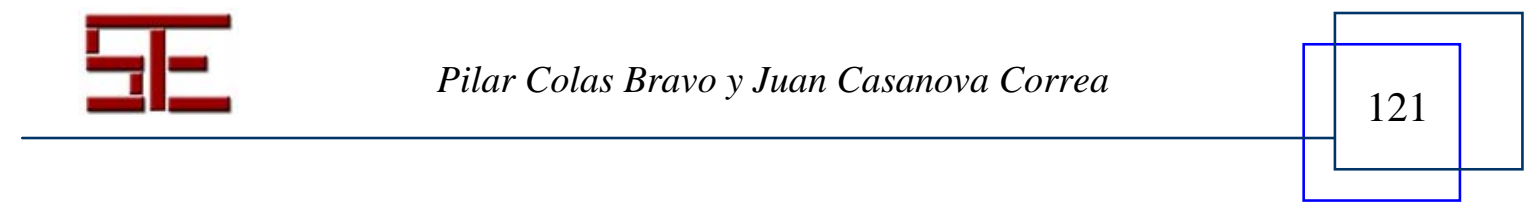




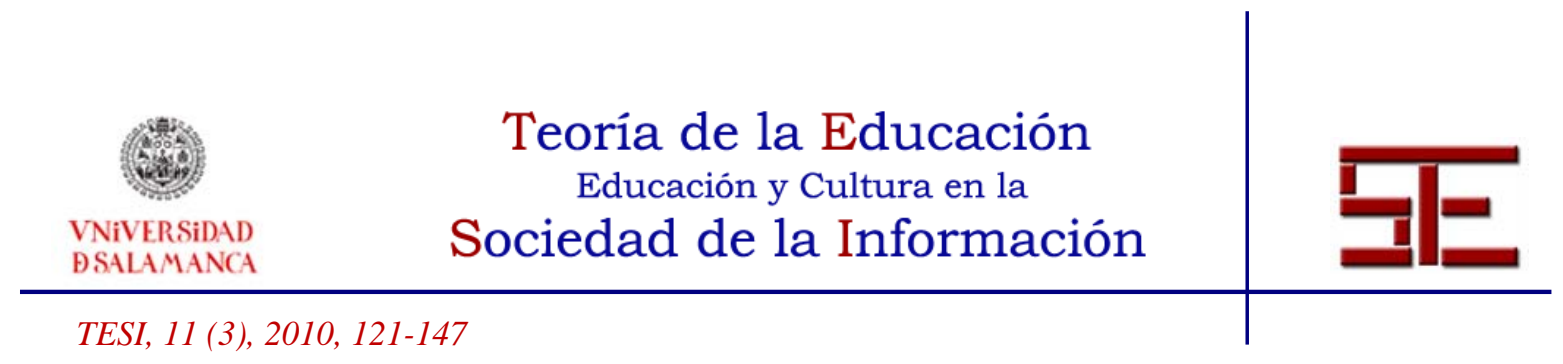

\title{
TEACHER AND SCHOOL VARIABLES THAT GENERATE GOOD PRACTICES WITHICT
}

\begin{abstract}
:
In this article the results of a case study carried out are presented by means of narrative interviews, whose objective is to identify the determining factors of the good practices with ICT. The good practices with ICT are related to two scientific areas of study. One, above mentioned, related to the integration of the ICT in the educational systems and, another, connected with processes of innovation. In this contribution we present the state of the question related to determining factors of the good practices from both points of view. From there we situate the theoretical framework of this work since the perspective of the teachers. The qualitative analysis carried out by means of the program AtlasTi identifies personal and contextual factors associated to the processes of innovation.
\end{abstract}

Key words:

Innovation, Teachers, Good practices, ICT, Features which have influential in use of ICT.

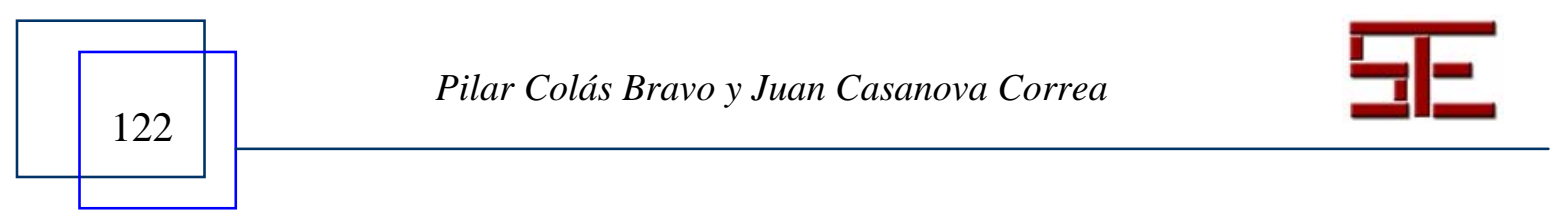




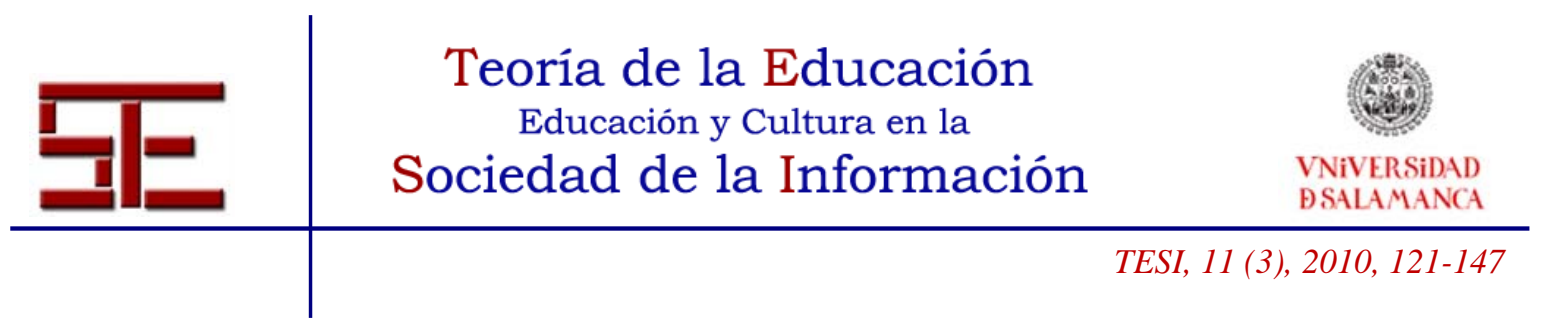

\section{VARIABLES DOCENTES Y DE CENTRO QUE GENERAN BUENAS PRÁCTICAS CON TIC.}

Fecha de recepción: 22/03/2009; fecha de aceptación: 27/10/2009; fecha de publicación: 28/02/10

Pilar Colás Bravo

pcolas@us.es

Universidad de Sevilla.

Juan Casanova Correa

juancasanova@uca.es

Universidad de Cádiz.

\section{1.- INTRODUCCIÓN}

El concepto de "buenas prácticas” se extiende y utiliza en muy diferentes ámbitos: empresarial, social, organizativo, financiero, educativo, etc., y por tanto en cada caso adopta definiciones ajustadas a los mismos. Nosotros en este estudio adoptamos el concepto planteado por De Pablos \& González (2007). Para estos autores las "buenas prácticas” no deben entenderse como la mejor actuación imaginable sobre un contexto específico, sino actuaciones que suponen una transformación de las formas de funcionamiento habituales y que constituyen el germen de un cambio positivo en las prácticas tradicionales. Este concepto es el que guiará la selección del caso objeto de este estudio, estando estrechamente ligado al concepto de innovación educativa.

La innovación educativa, en el marco de esta investigación, es entendida como el conjunto de iniciativas que inducen a los profesionales a pensar de un modo nuevo en la forma que tienen de hacer sus tareas. Como afirma Landow (2004) no se trata de un manejo ambicioso del concepto en el sentido de que los cambios venidos de la innovación sean radicales o totales, sino que esos modos nuevos de hacer las cosas puedan conducir a un cambio beneficioso, aunque no tenga éxito o no dure mucho tiempo. Sin embargo, aportan el valor de repensar la enseñanza y el aprendizaje (De Pablos y González, 2007).

La innovación educativa es un proceso complejo y dinámico que conlleva y origina transformaciones de distinta índole, pudiendo afectar tanto a las actuaciones docentes, como a los aprendizajes de los alumnos, al clima, sistemas organizativos de los centros, etc.

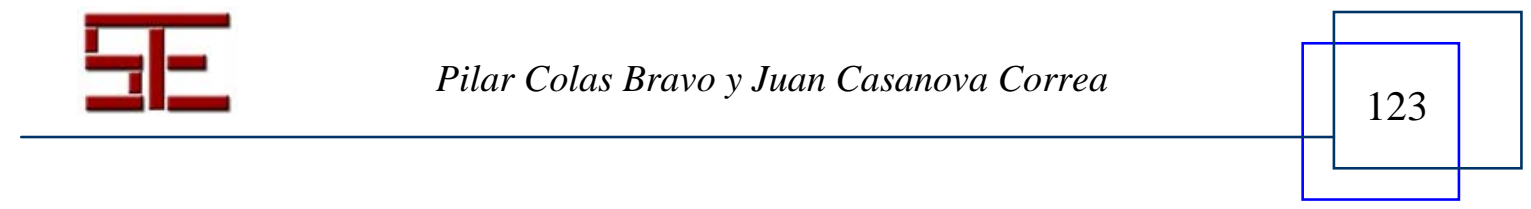




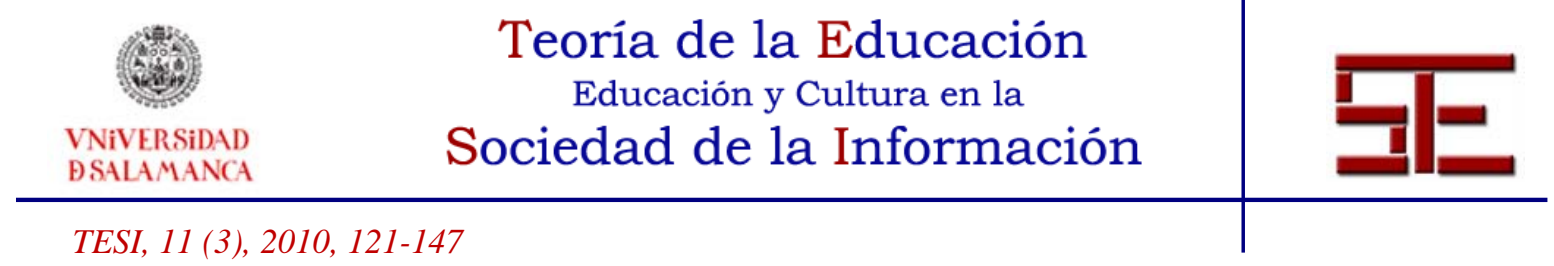

Además, la integración de las TIC conlleva procesos de implementación que pueden ser analizados también desde una perspectiva temporal, estudiando sus fases y sus condicionantes.

Desde un punto de vista científico las buenas prácticas con TIC están asociadas a dos áreas científicas de estudio. Una referida a la integración de las TIC en los sistemas educativos $\mathrm{y}$, dado que las buenas prácticas implican cambios y mejoras, otra a aportaciones científicas procedentes de procesos de innovación en las instituciones educativas.

De ahí que el marco teórico de este trabajo debamos situarlo en la confluencia de modelos teóricos; unos referidos a la integración de las TIC y otros a los procesos de innovación. Ello hace que sea necesario abordar estas dos perspectivas.

\section{2.- LA INVESTIGACIÓN SOBRE LA INTEGRACIÓN DE LAS TIC EN EL SISTEMA EDUCATIVO}

Existe una abundante producción científica sobre la integración de las TIC en los sistemas educativos, derivada de investigaciones desarrolladas a partir de los años 90. Los resultados de las mismas convergen en la idea de que existen distintos niveles de integración de las TIC. De Pablos (2000) identifica tres niveles de implantación: Introducción, Aplicación e Integración. Cada uno representa formas diferenciadas de incorporación de las TIC en los centros escolares. Para llegar a un nivel de Integración, nivel que se identifica con la plena incorporación de las TIC a nivel institucional y en el proceso instruccional, es necesario superar los dos niveles anteriores: una etapa de Introducción, que fundamentalmente implica la correspondiente dotación de los medios a los centros educativos y su familiarización por parte de los docentes. Y una fase de Aplicación en la que los docentes tratan de superar un conocimiento simplemente instrumental, característico de la fase anterior, y de una manera práctica o de primera mano van conociendo las aplicaciones básicas de estos medios en su campo específico de actividad docente. Esta conceptualización es contrastada empíricamente en centros educativos escolares de enseñanza primaria y secundaria (De Pablos \& Colás, 1998). Los resultados obtenidos apuntan a que la implantación de las TIC en los centros educativos se sitúa básicamente en los primeros niveles de Introducción y Aplicación. El nivel de Integración, no se manifiesta de forma consistente en la práctica y, por tanto, no llega a constituir un "cluster" con entidad propia. Se detecta, no obstante, en un grado incipiente y de forma puntual en determinados centros, variables vinculables a lo que conceptualizamos como "Integración". En esta investigación además se detectan seis factores asociados al uso de las TIC en los centros escolares: 1) uso e infraestructura de las TIC en los centros escolares, 2) iniciativas y actitudes hacia las TIC por parte del

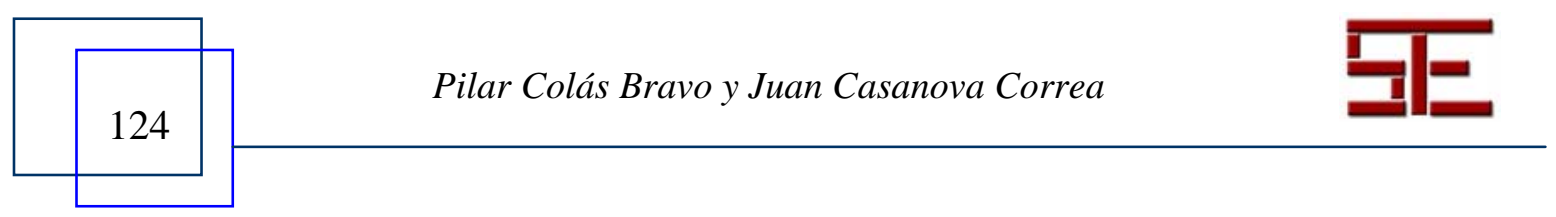




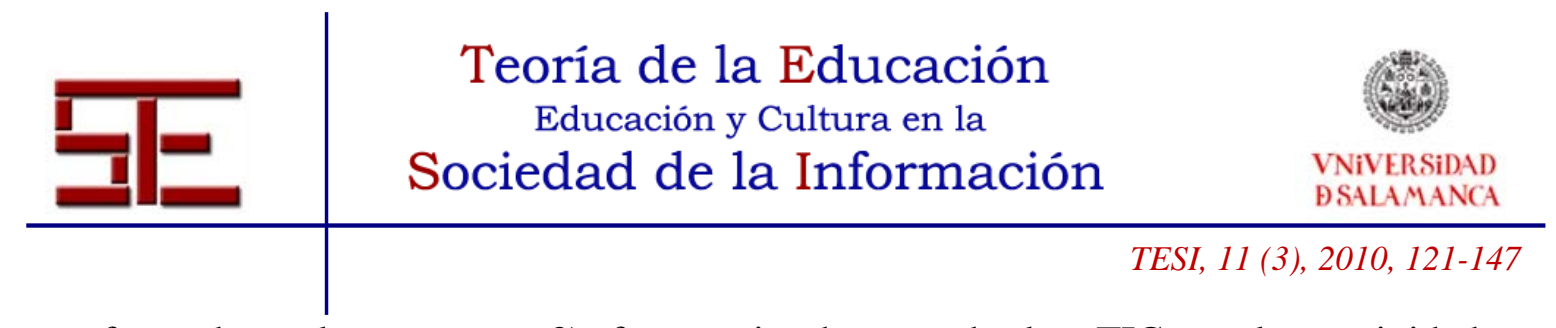

profesorado y los centros, 3) frecuencia de uso de las TIC en las actividades curriculares, 4) producción de materiales, 5) información sobre las TIC y 6) contexto escolar (Colás, 2001/2002).

También en esta línea se sitúan trabajos internacionales de investigación que tratan de identificar variables asociadas a la integración de las TIC en los centros educativos (Tearle, 2003; Meelissen, 2005). En estos estudios es frecuente centrarse en variables "inputs" tales como ratio alumno/ordenadores, infraestructuras, recursos, etc. Otras aportaciones inciden sobre aspectos contextuales tales como cultura del centro, el liderazgo, influencias externas, etc.

Por tanto, los resultados empíricos obtenidos indican que el grado de implantación de las TIC en los centros educativos no es homogéneo, ni extensivo.

En los últimos años el fuerte desarrollo de las TIC, unido a la implantación de políticas educativas destinadas a dotar de medios tecnológicos las escuelas, está cambiando el panorama educativo en materia de integración de las TIC en las instituciones escolares, permaneciendo, no obstante, diferencias en sus usos y aplicaciones. Algunos estudios actuales Tondeur, Valcke \& van Braak (2008), demuestran que existen diferencias entre las escuelas. Hay un porcentaje de la varianza entre escuelas (entre el 5-35\%, según los estudios) que se explica por políticas, así como por prácticas educativas, ambiente y clima de aprendizaje de la escuela. También se ha encontrado una escasa influencia de las variables "inputs" o recursos en los países desarrollados que expliquen el uso de las TIC, excepto en los aspectos relacionados con la formación y experiencia del profesorado.

En estos estudios se concluye que la extensión y aplicación de las TIC en los centros educativos es muy variada y en una gran mayoría de casos muy limitada. No cabe duda de que las políticas educativas emprendidas para potenciar las TIC en los centros educativos están potenciando e incrementando un uso efectivo de las TIC en el currículo escolar, sin embargo, las Buenas Prácticas siguen siendo bastante poco comunes. Es decir, aquí nos encontramos con un rango de posibles usos pedagógicos de las TIC que van desde los usos más frecuentes y habituales hasta los posibles usos que todavía no están creados. Es en este espacio en el que discurren las Innovaciones y Buenas Prácticas con TIC.

En estas creaciones tienen un papel fundamental los objetivos educativos y la interpretación del valor pedagógico otorgado a las TIC. Así en algunos centros toman la opción de centrar su esfuerzo en la provisión de TIC, entendiendo que éstas tienen consecuencias en el desarrollo de competencias tecnológicas en los estudiantes. En otros casos la interpretación pone el acento en el potencial de las TIC para que el

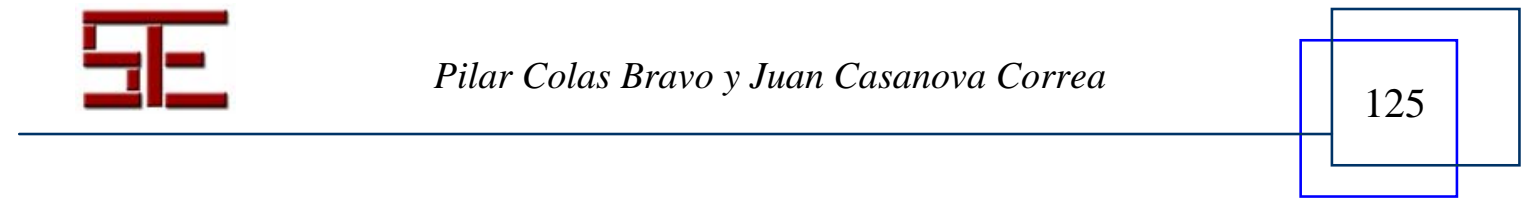




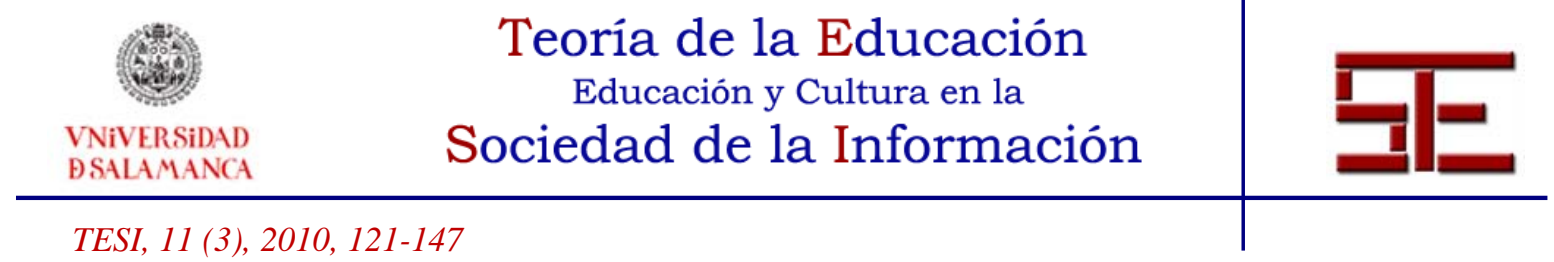

alumno alcance autonomía en el aprendizaje. Asimismo se detectan formas distintas de inclusión de las TIC en los centros educativos, existiendo ejemplos en los que se crean nuevos usos de las TIC de forma aislada dentro de un determinado centro, o ejemplos de un uso específico de las TIC que se extiende a todo el centro.

La investigación internacional se ha ocupado en las últimas décadas de estudiar los factores y procesos de integración escolar de las TIC (Nachmias y otros, 2004; Tondeur, Valcke y Van Braak, 2008; Loveless, y Dore, 2002; Karagiorgi y Charalambous, 2004). En dichas revisiones se ha puesto en evidencia que el proceso de uso de las nuevas tecnologías en los sistemas escolares es complejo.

La experiencia acumulada durante estos últimos años sobre la implementación de innovaciones pedagógicas usando las TIC aconseja estudiar las innovaciones tecnológicas exitosas teniendo en cuenta los contextos de referencia, ya que se reconoce la ineficacia de estudiar la innovación tecnológica aislada de los contextos educativos concretos. Por tanto, se recomienda estudiar la integración de las TIC en los grupos y contextos educativos reales, analizando los factores, efectos y procesos educativos que conllevan dichas innovaciones. Desde un punto de vista metodológico se observa una tendencia hacia estudios de corte más cualitativo e interpretativo dirigidos a conocer mejor los contextos reales de enseñanza.

El estudio de un caso de buena práctica nos da la oportunidad de desvelar el modelo de integración que se adopta en un contexto educativo concreto. Nuestro estudio se centra en un estudio de caso, valorado como ejemplos de buenas prácticas con TIC. Estas buenas prácticas se caracterizan por integrar las TIC en el currículo, enlazando la enseñanza y el aprendizaje. Y constituyen casos especiales, en tanto estos usos no son extensivos a la mayoría del profesorado. Su análisis nos ofrece la oportunidad de descubrir el modelo de integración que se adopta, así como la interpretación que en este caso se hace de las TIC en el proceso educativo.

Asimismo la exploración de un caso de buenas prácticas nos ofrece la oportunidad de explorar los factores que condicionan la existencia y extensión de las buenas prácticas con TIC en los centros escolares, desde la perspectiva de los propios agentes innovadores.

\section{3.- LA INVESTIGACIÓN SOBRE LA INNOVACIÓN PEDAGÓGICA CON TIC}

Esta temática ha ocupado el interés de numerosas investigaciones. Se ha considerado que este conocimiento sería útil para orientar las políticas educativas TIC, así como para la toma de decisiones sobre recursos humanos y financieros.

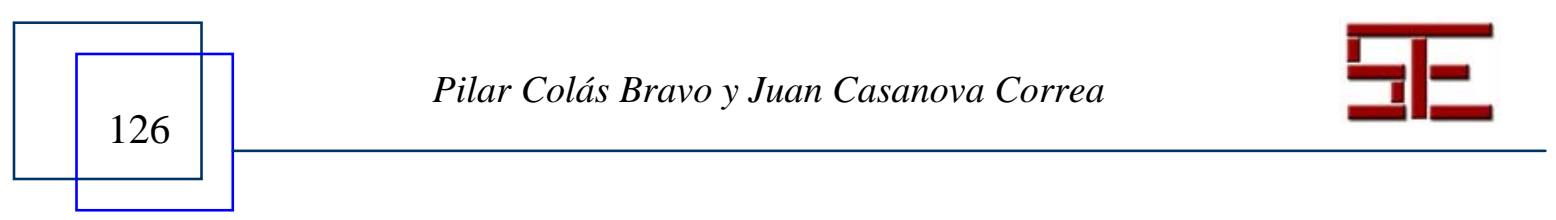




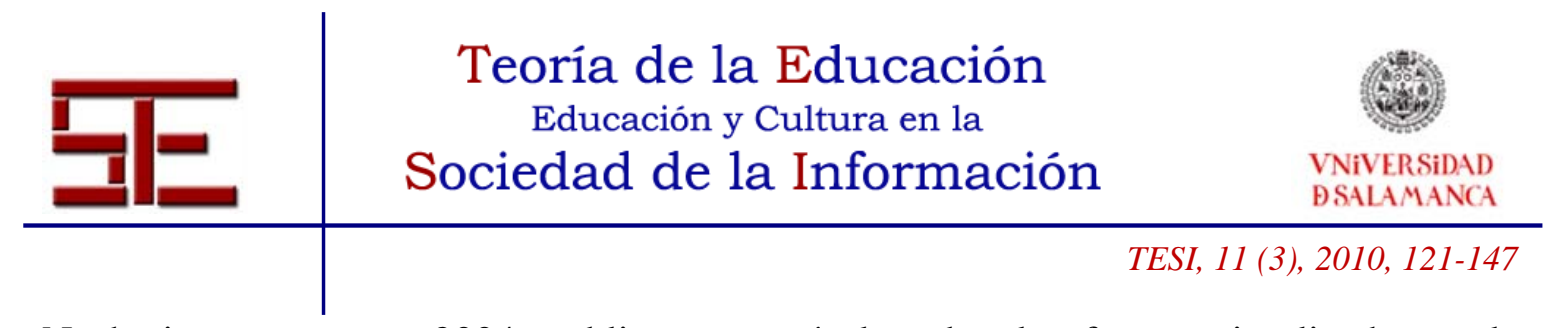

Nachmias y otros, en 2004, publican un artículo sobre los factores implicados en la innovación pedagógica utilizando las TIC. La revisión científica de aportaciones en este sentido identifica varias líneas de trabajo. Una primera línea se centra en factores potenciadores e inhibidores de cambios educativos en general (Fullan, 2001; Kinsler \& Gamble, 2002), y con las TIC de forma específica (Mioduser, y otros 2003). En estas revisiones se identifican factores de índole organizacional, incluyéndose el profesorado y cómo éste hace frente a las demandas de cambio (van Braak, J. 2001). Una tercera línea de trabajos se centra en factores externos a los centros (Venezky \& Davis, 2001). En todas ellas existe el interés por estudiar de forma sistemática, la generación, desarrollo e implementación de las innovaciones educativas, poniendo especial énfasis en aquellos factores que afectan al proceso. Nachmias (2004), a partir de estas revisiones sistematiza los factores que condicionan las innovaciones con TIC en torno al centro y la actividad didáctica. En esta aportación se identifican como factores clave: las políticas TIC, liderazgo y coordinación en TIC, infraestructuras, clima y organización del centro, formación de staff educativo y relaciones con el entorno. El análisis del peso de estos factores en la innovación le lleva a concluir que la infraestructura, el clima de centro y los roles de los agentes educativos son los factores con mayor incidencia en las innovaciones. El profesorado es un factor esencial en la introducción de cambios en los centros educativos. Esta afirmación queda respaldada en numerosos estudios (Van Braak, J. 2001).

Otra línea de trabajos opta por un enfoque más holístico. Se asume una relación integral y multidimensional entre factores personales, pedagógicos y organizativos (Zhao \& Frank, 2003; Kozma; 2003).

Tearle (2003), en una revisión de ambas líneas de trabajo (Innovación y TIC), sistematiza los factores, procedentes de uno y otro modelo, considerados relevantes por la investigación científica en este campo en una propuesta integrada. En su modelo destaca el peso otorgado a factores humanos y personales, en los que descansa y se articula la innovación con TIC.

También otros trabajos (Kim, 2000) confirman la importancia de la motivación personal del profesorado y su fuerte sentido de responsabilidad social, como aspectos claves de la innovación con TIC, unido a una inquietud constante de mejora y evaluación de las prácticas implementadas desde distintas ópticas.

La revisión del estado de la cuestión hasta aquí presentada desde la perspectiva de la integración de las TIC en los centros escolares y de la innovación educativa, nos lleva a la conclusión de que el profesorado es una variable o factor importante desde ambas perspectivas.

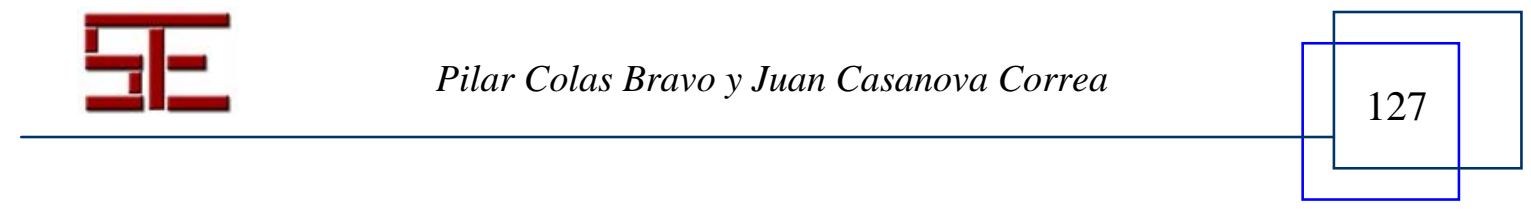




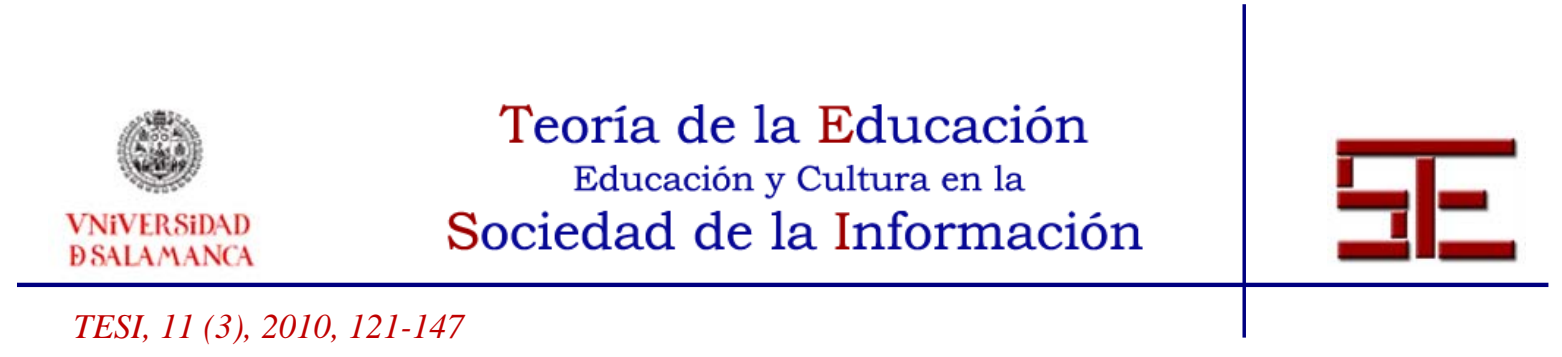

\section{4.- CARACTERÍSTICAS DEL PROFESORADO QUE ASUME PRÁCTICAS DE INNOVACIÓN CON TIC}

Tondeur, Van Braak \& Valcke (2007) estudian de forma más específica las variables referidas al profesorado que sistematizan en torno a una dimensión estructural y otra cultural. En la primera se incluyen como variables "la experiencia en informática" y el "género". En la dimensión cultural "las creencias del profesor sobre lo que considera buena formación” y las “actitudes hacia la informática”, así como la experiencia del profesor, sus creencias, emociones, conocimientos, habilidades y motivaciones. Aspectos todos ellos que interaccionan con el contexto de aprendizaje. El profesor adopta una posición de continuo aprendiz, siendo el centro de los procesos de cambio educativo (Hennessy y otros 2005). Sobre la relevancia de estas variables existen otras investigaciones que avalan su peso en los procesos de innovación con TIC. Así, Niederhauser y Stoddart (2001) indican que las acciones innovadoras y cambios en los métodos de enseñanza están influenciados tanto por lo que los profesores creen como por lo que conocen. Las experiencias propias también influyen en su deseo de aprender y comprometerse con actividades de innovación educativa. Por otra parte, también existen abundantes investigaciones sobre el efecto de las actitudes docentes sobre la innovación con TIC (Gobbo \& Girardi, 2001; Loveless 2003). Estos trabajos indican que existe una relación muy directa entre la actitud positiva hacia las TIC y su utilización dentro del aula.

Otros aspectos extraídos de estudios empíricos son el deseo de innovar y los conceptos educativos que los profesores manejan. La disposición a la innovación del profesorado lleva parejo un conocimiento claro de la innovación, actitudes favorables y una intención o propósito firme de innovar (Van Braak, 2001). Este autor, en un trabajo posterior (2004), confirma que el "deseo de innovar" es un factor determinante que explica el uso de las TIC en las clases. También cabe destacar que las creencias educativas del profesor se asocian con usos específicos de las TIC (Ertmer, 2005; Song y otros, 2007). Otros estudios (Niederhauser \& Stoddart, 2001) también coinciden afirmando que el uso de las TIC se corresponde a unas determinadas creencias sobre la enseñanza o sistema de creencias. En este sentido algunos estudios muestran que un bajo uso de las TIC está asociado con estilos de enseñanza centradas en el profesor, mientras un alto nivel de uso tiende a estar asociado con prácticas constructivistas y centradas en el alumno (Ertmer, 2005).

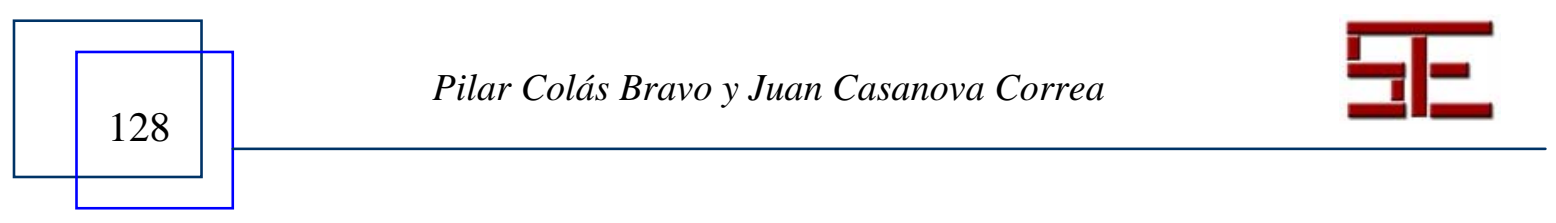




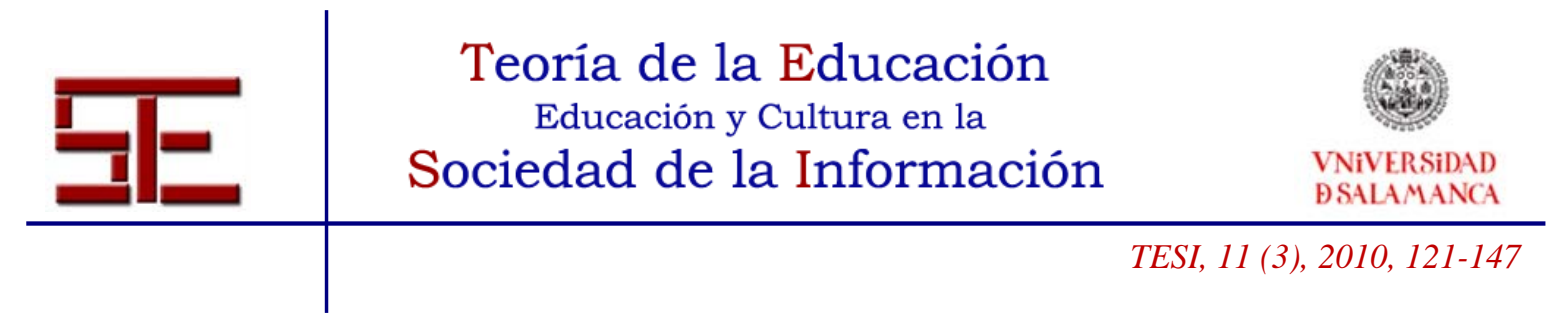

En la Figura 1 se relacionan las variables planteadas en las revisiones realizadas.

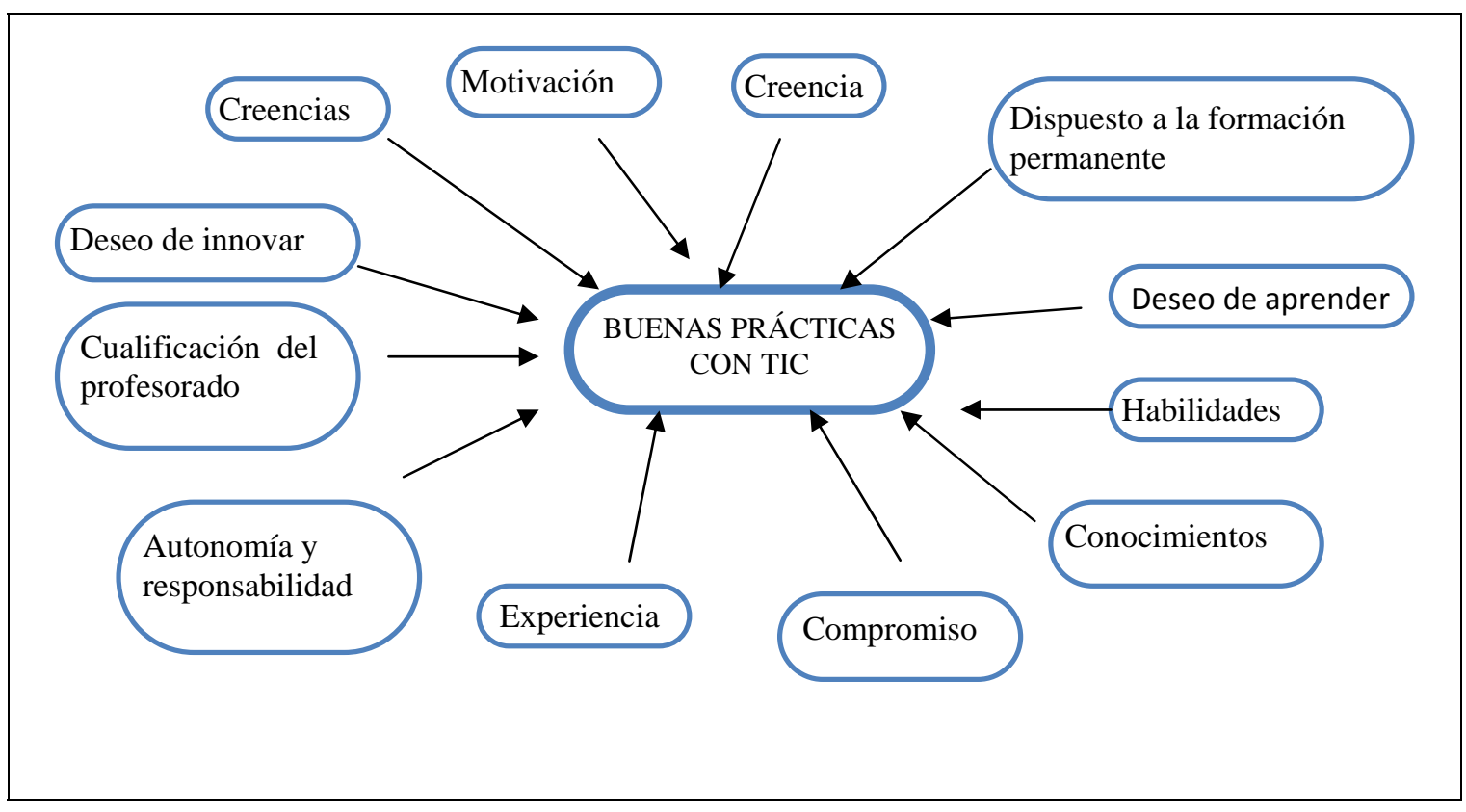

Fig. 1. Factores asociados a buenas prácticas con TIC relacionadas con el profesorado.

Como hemos mostrado, las buenas prácticas con TIC se fundamentan en la implicación del profesorado. Esta implicación se asienta a su vez en numerosas variables, tal y como quedan descritas en la Figura 1. Por ello la línea de trabajo que aquí planteamos es dar la voz y palabra al profesorado, para indagar sobre "qué es lo que hace que nazcan y permanezcan buenas prácticas con TIC”. Se trata de un enfoque cualitativo centrado en la narración que el profesor hace de su experiencia de innovación. Este estudio cualitativo trata de identificar los factores condicionantes de las buenas prácticas con TIC desde la perspectiva y mirada del profesor, agente de las buenas prácticas.

\section{5.- DISEÑO DE LA INVESTIGACIÓN}

\section{1.- Objetivos e interrogantes de la investigación}

Desde una perspectiva científica el principal objetivo de este estudio es indagar en los factores asociados a los procesos de innovación con TIC que plantea el profesorado, en casos de contextos culturales españoles. Es decir, si las buenas prácticas con TIC identificadas en centros escolares españoles podrían ser explicadas por los factores

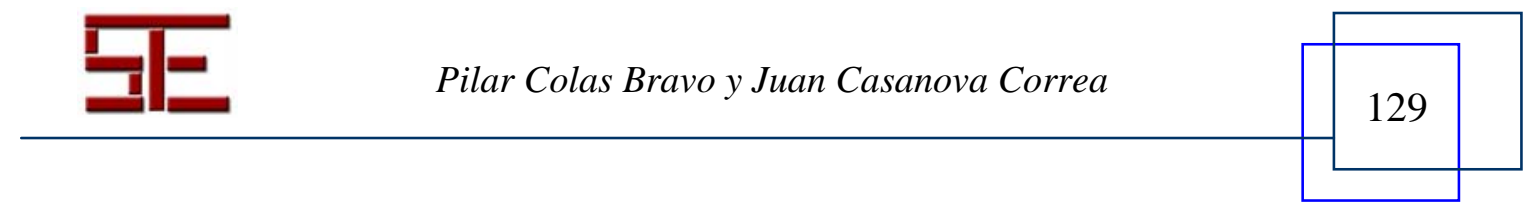




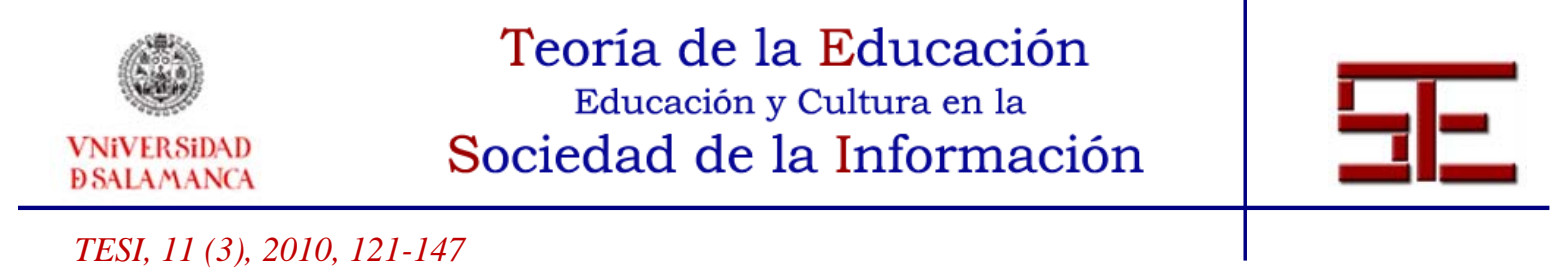

reconocidos e identificados en los modelos teóricos, elaborados en base a las revisiones de las investigaciones realizadas, que en la mayoría de los casos proceden de otros contextos culturales. A esto se une otra inquietud científica, la de explorar las conexiones existentes entre estos factores. Aspecto no incluido en las revisiones realizadas.

Con esta investigación se trata de responder a los siguientes interrogantes:

¿Qué factores están asociados a las buenas prácticas desde la mirada del profesorado? ¿Cuál es la relación que se establece entre estos factores?

¿Cómo se genera, mantiene y desarrolla el proceso de buenas prácticas con TIC?

Los resultados de este estudio permitirán esbozar una aproximación a un modelo teórico de factores que condicionan las Buenas Prácticas desde la perspectiva del profesorado, agente principal de las mismas.

\section{2.- La selección del caso de buenas prácticas con TIC}

El proceso seguido en la selección del caso de este estudio consta de las siguientes fases:

a) Primera fase: determinación de la población.

b) Segunda fase: selección de la muestra.

c) Tercera fase: selección del caso.

La población la constituyen todos los centros escolares de educación primaria y secundaria de la Comunidad Autónoma de Andalucía y específicamente de la provincia de Cádiz. En esta primera fase se identifican la totalidad de centros de Primaria y Secundaria que cumplían con unos requisitos mínimos. A saber, que sean calificados por la Consejería de Educación de la Junta de Andalucía como centros TIC y/o participen en proyectos de innovación, experiencias con TIC, y que hayan generado recursos o prácticas bajo el auspicio de políticas educativas de la Junta de Andalucía, dirigidas a innovaciones con TIC. En el comienzo de esta investigación, se contabilizan 280 centros en Andalucía con estos requisitos, 59 de los mismos se ubicaban en Cádiz. La propia administración educativa considera que estos centros incorporan las TIC como herramienta educativa en la enseñanza-aprendizaje, donde la informática se usa para aprender, es decir, más allá del simple hecho de aprender informática.

Para la segunda fase, selección de la muestra, recurrimos a los Centros de Profesorado (CEPs) de la provincia de Cádiz. En los contactos mantenidos solicitamos nos

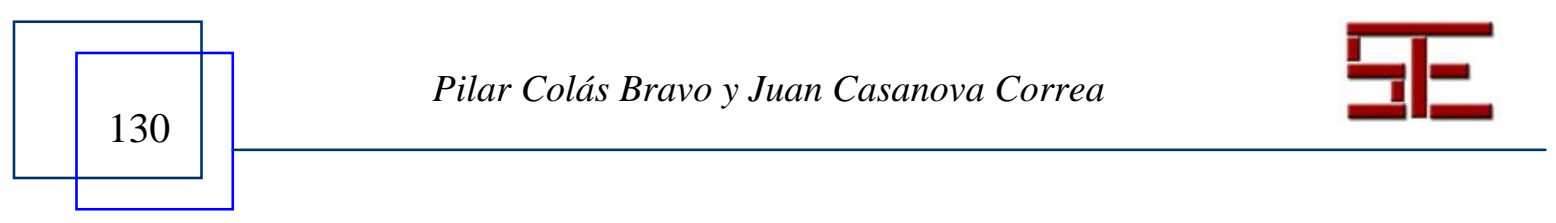




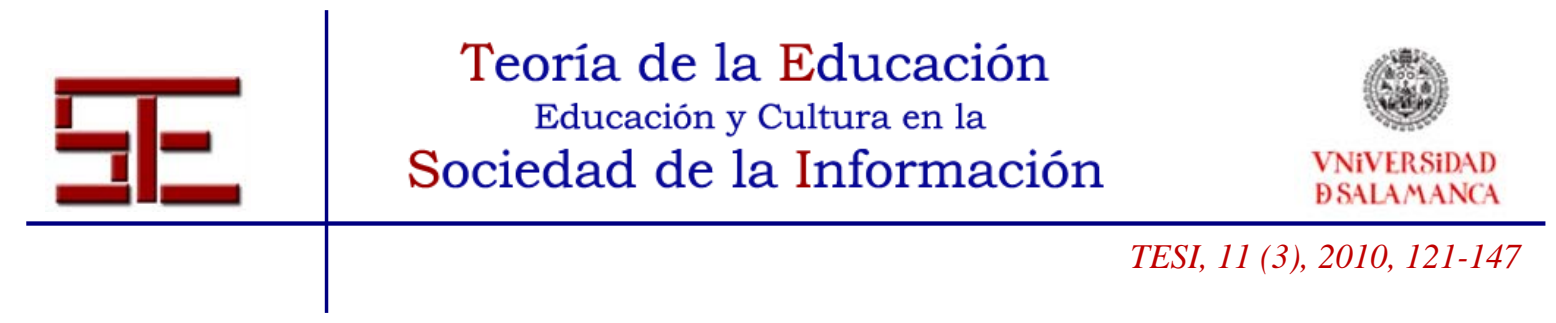

identificaran aquellos centros que consideraban que podían ser tomados como ejemplos a resaltar de buenas prácticas. Se identificaron ocho centros.

En la tercera fase se incluía una primera visita a cada centro para presentar el proyecto al equipo directivo del mismo, y especialmente al coordinador/a TIC del mismo. Se les solicitaba indicaran qué docente podría ser seleccionado por llevar a cabo buenas prácticas con TIC. De estas recomendaciones se obtuvo un caso de Buenas Prácticas con TIC.

El caso seleccionado ha sido el de una maestra de primaria con 16 años de experiencia docente en el mismo centro. Se trata de una maestra preocupada por 'ilusionar' a su alumnado con la materia que imparte, sin formación en ningún tipo de tecnología digital, pero que ha llegado a integrar las TIC en sus actividades docentes. ¿Por qué hemos seleccionado este caso como un caso de buenas prácticas con TIC? ¿Cuál ha sido la innovación que ha incorporado para ser merecedora de nuestra atención? Se trata de un caso que ejemplifica el conjunto de procesos que pueden darse para que se realice una incorporación exitosa de las TIC en los centros escolares, partiendo de unas condiciones muy desfavorables iniciales (rechazo manifiesto a las TIC “tecnofobia' y nula formación en ellas). En este caso también quedan ilustrados multitud de factores que tienen incidencia e influyen para introducir innovaciones con TIC en el currículum. También ejemplifica un proceso de 'alfabetización digital' docente que pasa por el descubrimiento de las posibilidades didácticas que le ofrecen las TIC. Desde el punto de vista de los aprendizajes de los alumnos este caso muestra los efectos de la innovación: motivación intrínseca del alumnado por el uso de Internet y los ordenadores, aumento de autonomía en su aprendizaje, y asunción, por parte del alumno, de un rol más activo en su aprendizaje.

Los párrafos siguientes extraídos de la información aportada por la profesora ilustran lo anteriormente referido.

El alumnado se motiva:

“...normalmente están en clase callados, trabajando los bloques de contenidos muy bien, muchos solos, y animados. "(Párrafo 24)

“...los que no trabajan normalmente son los que les encanta el ordenador y te lo mandan.” (Párrafo 94)

"Sí, claro, yo quiero que la vean todos, lo que sí está claro es que esto a ellos no se les va olvidar porque lo han hecho ellos y están orgullosos, me dicen señorita ¿los va a ver todo el mundo? Y yo, sí, todo el mundo lo va a ver."(Párrafo 110)

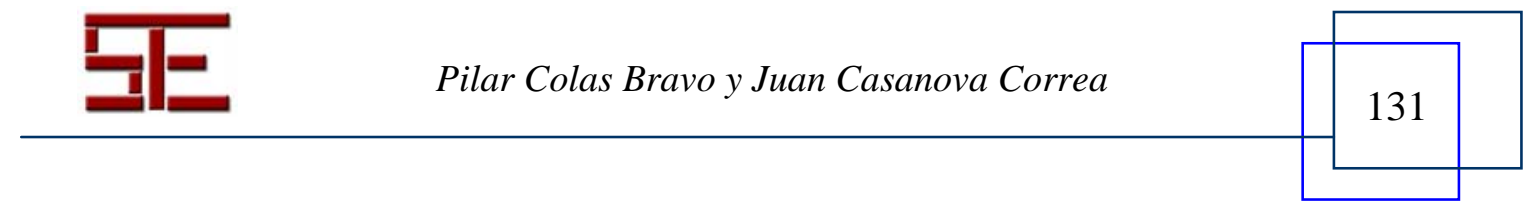




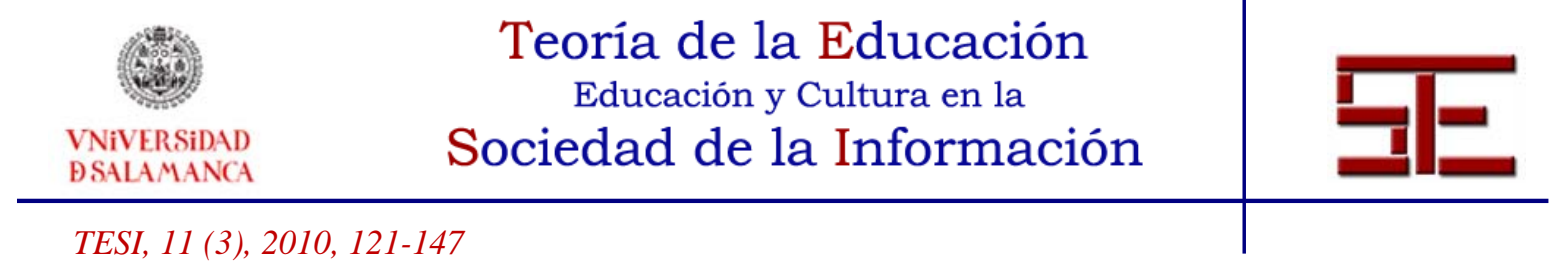

El alumnado se vuelve más autónomo

“El afianzar lo que yo quiero transmitir, porque es que las imágenes... yo le veo muchísimas posibilidades, porque los niños aprenden involuntariamente, yo te aseguro a ti que los que me van a hacer la presentación, ellos van a pasar al instituto, y como ellos van a hacer esa presentación, ellos van a saber explicarlo, ... lo que es la cuestión formativa... me ha venido de lujo el ordenador." (Párrafo 24)

El alumnado aprende más y mejor.

"Yo te digo que sí, en mi área lo que es los conceptos y la documentación, con las TIC aprenden más que antes, porque están utilizando todos sus sentidos, y cuando yo me pongo ahí la hora entera a hablar, pues ellos son sujetos pacientes, sobre todo me ayudan las imágenes a la hora de explicar muchos conceptos que para mí no son abstractos, pero para ellos si, tienes que aterrizarlo como yo te digo, no concretizarlo, aterrizarlo y llevártelo tu a tú terreno, para que ellos asimilen. Eso no es fácil.” (Párrafo 38)

\section{3.- Técnicas de recogida de datos}

En el apartado anterior ya hemos indicado que optamos por la entrevista narrativa como técnica básica de recogida de datos. Esta técnica centra toda la información sobre la narración que hace el profesor de su actividad docente a lo largo del periodo de duración de las buenas prácticas. A través de su 'historia', nos narra su experiencia 'vital', en base a la interpretación que la profesora hace de lo acaecido. La narración muestra, por tanto, la elaboración cognitiva y la reconstrucción subjetiva de la buena práctica, en base a una interpretación personal de los hechos que la dota de significado. Por otra parte, la narración es dinámica abarcando los inicios, el desarrollo y situación actual de las buenas prácticas. En el relato se hacen patentes los cambios en el tiempo, a la vez que se revelan los aspectos de índole personal, contextual y circunstancias que forman parte de las distintas fases de los procesos de desarrollo de esta buena práctica. Por tanto, el relato otorga un carácter coherente y organizado a los eventos e incidentes a través del tiempo, estableciéndose relaciones de causalidad entre los hechos que explican cada momento. Otro valor de la narratividad estriba en su potencial para penetrar en las relaciones con los entornos socioculturales e interpersonales. Así en el relato se alude a contextos de referencia (centro, compañeros, grupos de trabajo, entorno familiar, etc.) que tienen significado en la experiencia concreta que se narra. Por tanto esta metodología permite observar los flujos entre la evolución personal y el contexto profesional, así como sus respectivas influencias. Lo que en suma se pretende

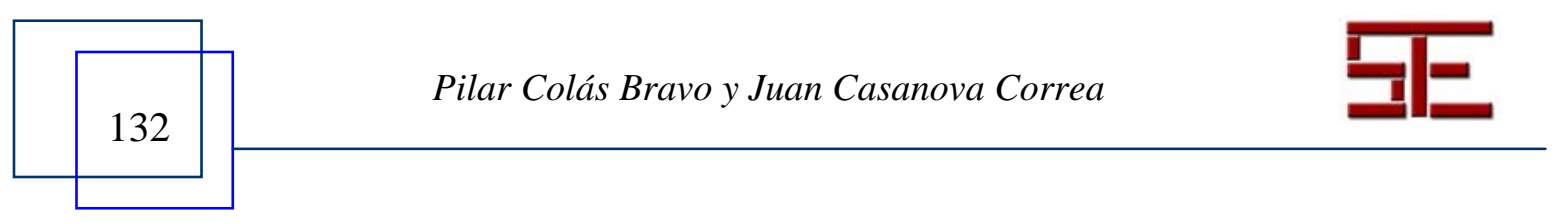




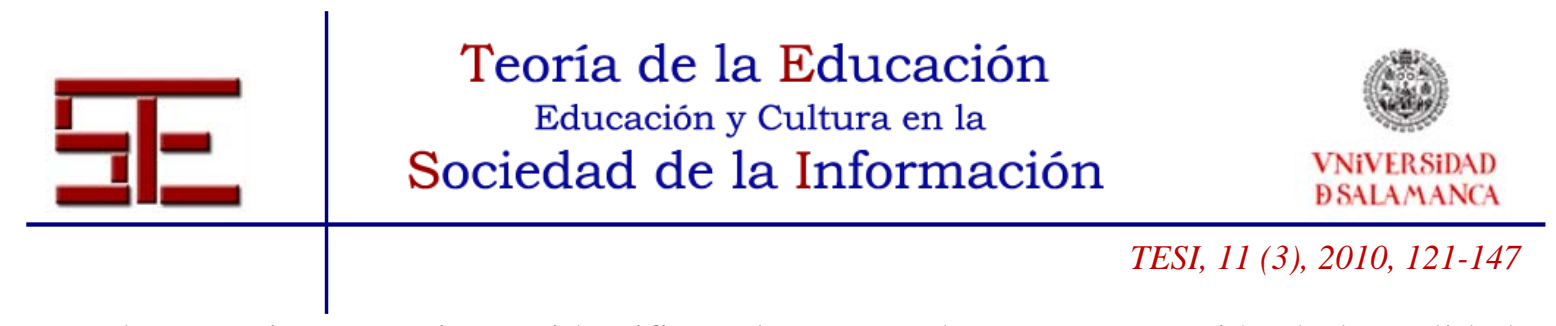

con la entrevista narrativa es identificar claves para la autocomprensión de la realidad analizada.

A nivel práctico se realizaron dos entrevistas, con una duración de entre una y tres horas. Las entrevistas siguen unas determinadas pautas metodológicas. La primera entrevista tiene por objeto situar el relato (las buenas prácticas) en un contexto, un tiempo y unas causas (motivación) concretos. Se conduce el relato de la experiencia, bajo una estructura narrativa que consta de tres fases: inicio, desarrollo y desenlace.

De esta primera sesión se elabora un resumen tan amplio como sea necesario. Este material sirve para que tanto entrevistador como entrevistado puedan reflexionar sobre la información recogida de las cuestiones iniciales. Este resumen se consensúa entre entrevistador y entrevistado y se comparte como elemento de reflexión para la segunda sesión.

En la segunda entrevista se utilizan aportaciones o hallazgos aparecidos en la primera sesión. El entrevistador debe tratar de apresar los temas generadores en la experiencia contada por el informante: los hilos de la trama que dan sentido a los cambios y avatares que se producen en la realidad. Estos puntos de inflexión o "plots" son fundamentales a la hora de retomar esta segunda entrevista, así como para analizar, posteriormente, las narraciones/entrevistas.

\section{4.- Análisis de datos}

Las entrevistas fueron transcritas y posteriormente fueron analizadas mediante el software científico Altas.Ti. 5.0. El análisis de la entrevista narrativa, en este caso se centra exclusivamente en los factores condicionantes favorecedores de las buenas prácticas. La información obtenida mediante las entrevistas narrativas nos permite obtener otra mucha información que no es objeto de este artículo.

El análisis cualitativo llevado a cabo sigue un proceso metodológico que consta de identificación de variables o factores, refinamiento de variables, establecimiento de relaciones entre variables y construcción de teorías mediante redes o Network.

\section{6.- RESULTADOS}

Uno de los primeros resultados obtenidos es que existen dos dimensiones asociadas a las buenas prácticas. Una dimensión personal y otra contextual, como puede observarse en la Figura 2.

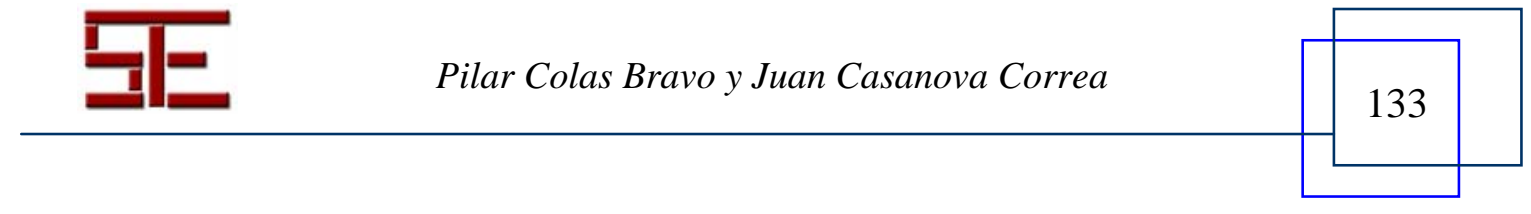



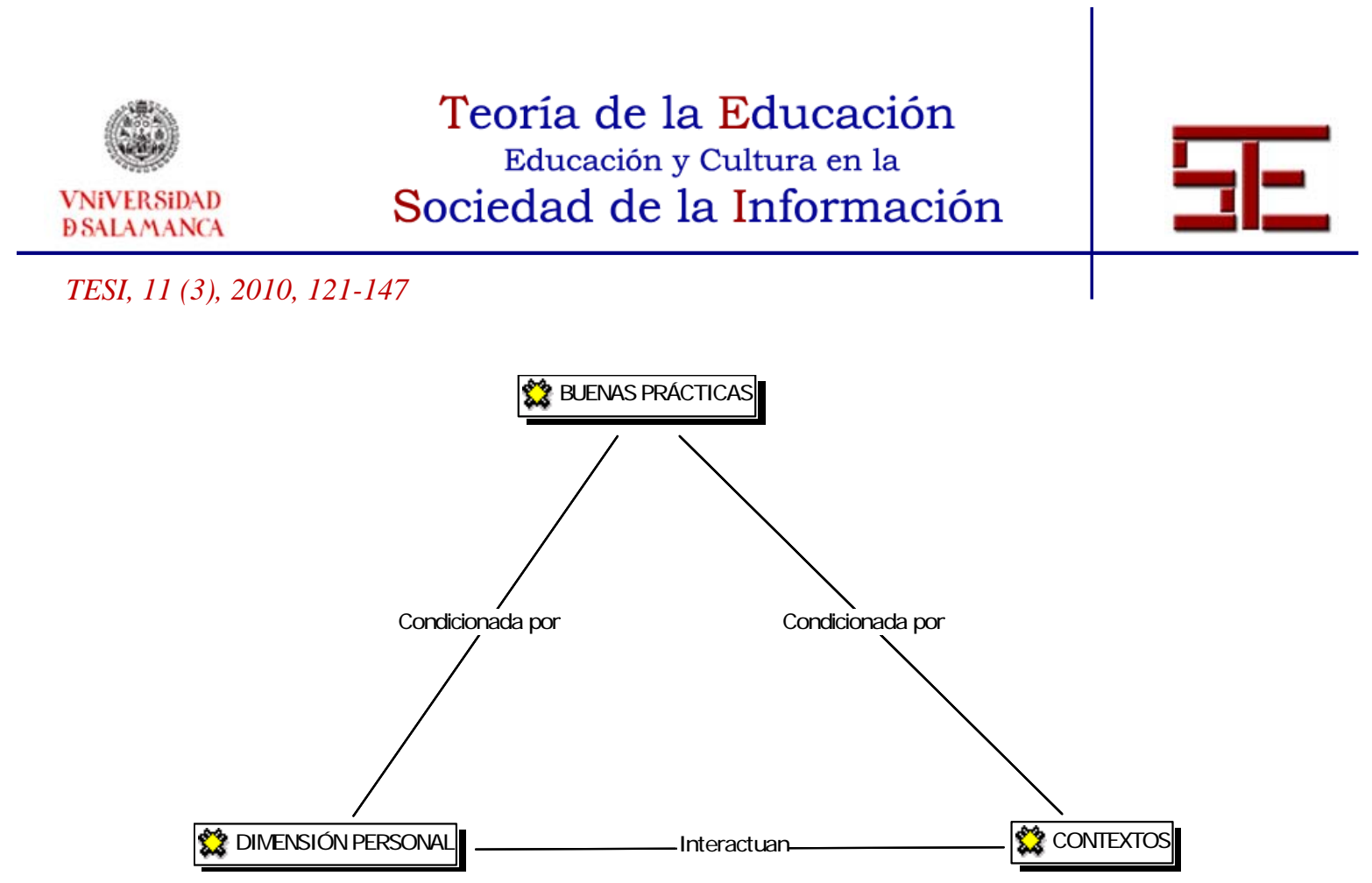

Figura 2. Dimensiones condicionantes de las Buenas Prácticas con TIC

\section{1.- Factores asociados a las buenas prácticas en la dimensión personal}

El análisis inductivo de los datos nos devela las siguientes variables relacionadas con aspectos de índole personal:
a) Nuevas posibilidades
b) Responsabilidad
c) Esfuerzo
d) Superación
e) Implicación
f) Concepción educativa
g) Satisfacción

En la Tabla 1 podemos ver cada variable relacionada con su concepto y un episodio narrativo ilustrativo.

\begin{tabular}{|c|c|c|}
\hline Variables personales & Concepto & Episodio Narrativo \\
\hline Nuevas posibilidades & $\begin{array}{l}\text { El uso progresivo de TIC en las } \\
\text { actividades de aula ofrece } \\
\text { nuevas posibilidades para el }\end{array}$ & $\begin{array}{l}\text { "Una última cosa importante, hicimos } \\
\text { un teatro y lo grabamos en vídeo y lo } \\
\text { pusimos en la plataforma y como } \\
\text { algunos padres no pudieron venir pues } \\
\text { compramos un reproductor, soy muy } \\
\text { cateta en este aspecto no se utilizar }\end{array}$ \\
\hline
\end{tabular}

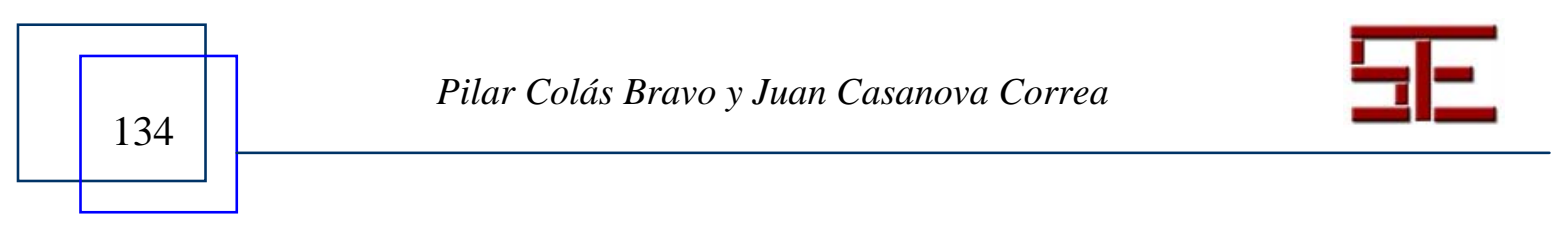




\begin{tabular}{|c|c|c|}
\hline H & \multicolumn{2}{|c|}{$\begin{array}{c}\text { Teoria de la Educación } \\
\text { Educación y Cultura en la } \\
\text { Sociedad de la Información }\end{array}$} \\
\hline & \multicolumn{2}{|r|}{ TESI, 11 (3), 2010, 121-147 } \\
\hline & $\begin{array}{l}\text { aprendizaje, la motivación y/o la } \\
\text { relación con las familias, no } \\
\text { contempladas con anterioridad }\end{array}$ & $\begin{array}{l}\text { términos en este aspecto, entonces } \\
\text { compramos una grabadora y le } \\
\text { grabamos un DVD con el teatro de sus } \\
\text { niños y se los regalamos." }\end{array}$ \\
\hline Responsabilidad & $\begin{array}{l}\text { La palabra dada obliga a su } \\
\text { cumplimiento }\end{array}$ & $\begin{array}{l}\text { "Yo, la verdad ,es que lo he hecho por } \\
\text { cuestión de conciencia, yo he firmado } \\
\text { y a mí me han educado en la } \\
\text { responsabilidad." }\end{array}$ \\
\hline Esfuerzo & $\begin{array}{l}\text { Las tareas a realizar usando TIC } \\
\text { requieren la realización de } \\
\text { actividades r formativas } \\
\text { complementarias y de tiempos } \\
\text { añadidos para la elaboración de } \\
\text { materiales. }\end{array}$ & $\begin{array}{l}\text { “...hace dos años, dije voy a hacer un } \\
\text { cursillo sobre los jotaclick, por la } \\
\text { tarde fuera de horarios y todo eso, yo } \\
\text { no vivo aquí, vivo en jerez y tengo } \\
\text { una familia grande y me costó } \\
\text { quedarme aquí hasta las } 8 \text { de la tarde, } \\
\text {..” }\end{array}$ \\
\hline Superación & $\begin{array}{l}\text { Las dificultades encontradas en } \\
\text { el aprendizaje del uso de TIC no } \\
\text { constituyen un obstáculo para } \\
\text { seguir conociendo su uso y } \\
\text { posibilidades didácticas }\end{array}$ & $\begin{array}{l}\text { “...lo primero que yo aprendí fue } \\
\text { bastantes J-click de...propios míos, } \\
\text { tengo por lo menos veinte o más,...”" }\end{array}$ \\
\hline Implicación & $\begin{array}{l}\text { La incorporación al proyecto } \\
\text { TIC no sólo conlleva hacer algo } \\
\text { con TIC, también hacerlo lo } \\
\text { mejor posible con las TIC }\end{array}$ & $\begin{array}{l}\text { “...Lo primero } \\
\text { religiosamente fue } \\
\text { ordenador...” }\end{array}$ \\
\hline Concepción educativa & $\begin{array}{l}\text { La pretensión última en la } \\
\text { enseñanza, además de que el } \\
\text { alumnado domine unos } \\
\text { contenidos, es que se produzcan } \\
\text { cambios en su concepción del } \\
\text { mundo y en su comportamiento. }\end{array}$ & $\begin{array}{l}\text { “... a mi no me interesa que los niños } \\
\text { se aprendan esto de memoria, lo que } \\
\text { tengo ahí metido (en la plataforma) es } \\
\text { para transmitir un mensaje relacionado } \\
\text { con el contenido...” }\end{array}$ \\
\hline Satisfacción & $\begin{array}{lcr}\text { La realización de } & \text { actividades } \\
\text { con TIC tiene como } & \text { como } \\
\text { consecuencia directa } & \text { la } \\
\text { sensación de alegría y contento. }\end{array}$ & $\begin{array}{l}\text { "Estoy metida, y estoy muy contenta, } \\
\text { pues si, la verdad es que si." }\end{array}$ \\
\hline
\end{tabular}

Tabla 1. Conceptualización de las variables de la dimensión personal

Estas variables se observan relacionadas entre ellas, aunque consideramos que giran en torno a dos variables fundamentales: la responsabilidad y la implicación con el trabajo docente. Podemos visualizarlo a través de la Figura 3 para una mejor comprensión.

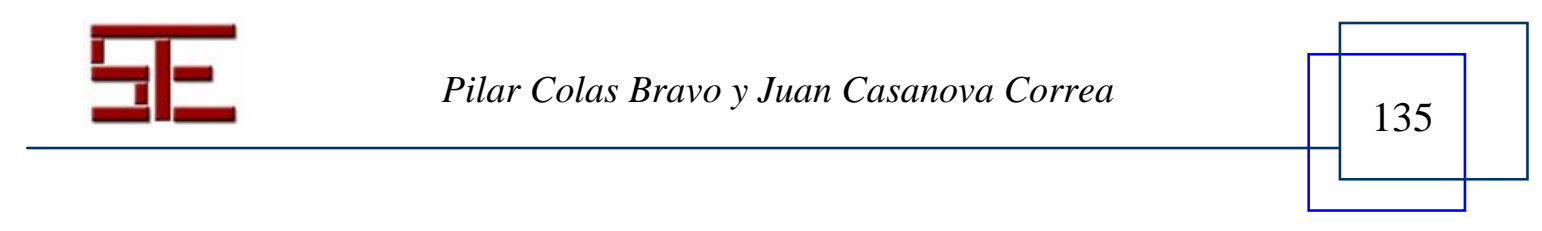



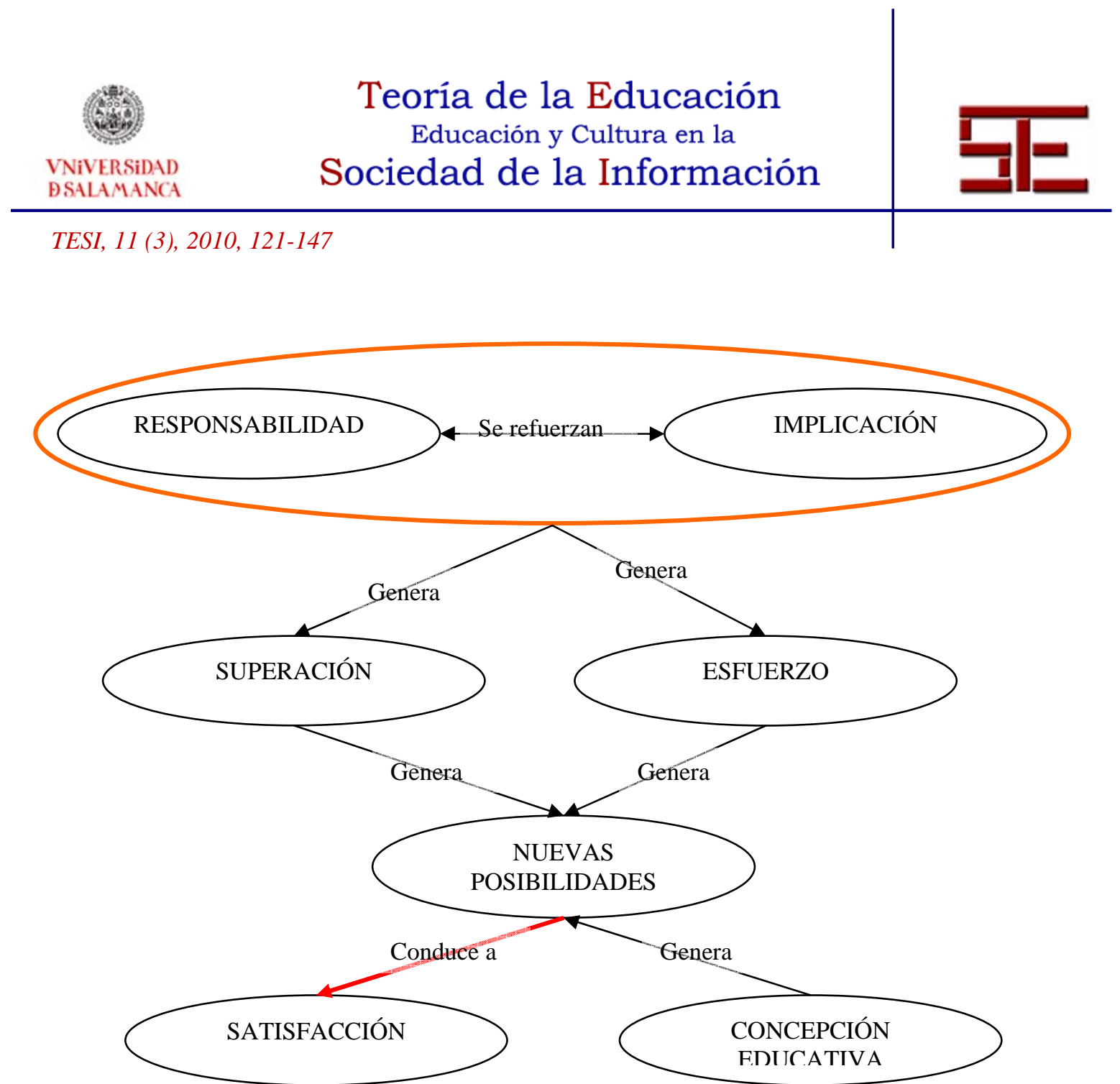

Figura 3. Relaciones observadas entre las variables personales

Pero estas variables han ido emergiendo del discurso docente siguiendo un proceso con una lógica histórica personal. Una lógica justificativa del momento en el que la entrevistada se encuentra. El proceso es secuencial, con un principio y un final, aunque el final se caracteriza por ser cíclico. Comentemos esta idea última tomando como referencia las propias palabras de la entrevistada.

En primer lugar, y de forma secuenciada en el tiempo, podemos identificar distintas fases:
A. Dejarse llevar por el grupo
B. Tomar conciencia de las propias limitaciones: bloqueo o 'tecnofobia'
C. Apelar al sentido de la propia responsabilidad
D. Acción hacia la práctica: formación y apoyo colaborativo
E. Satisfacción personal y profesional

La primera fase, dejarse llevar por el grupo, nos pone de manifiesto su interés poco entusiasta por el proyecto TIC que se inicia en su centro de trabajo, pero también su

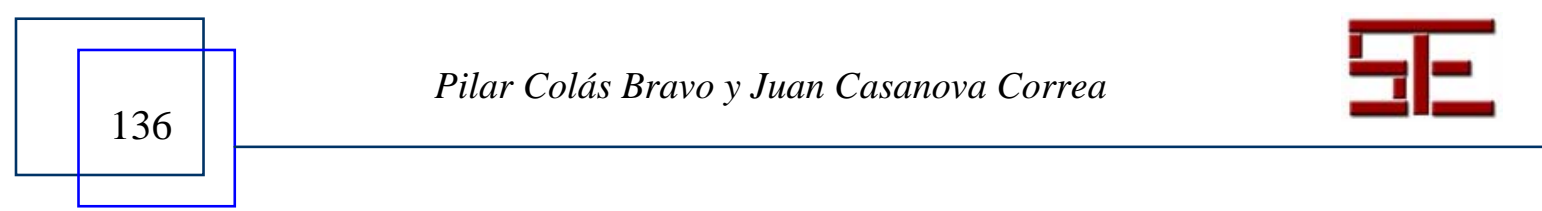




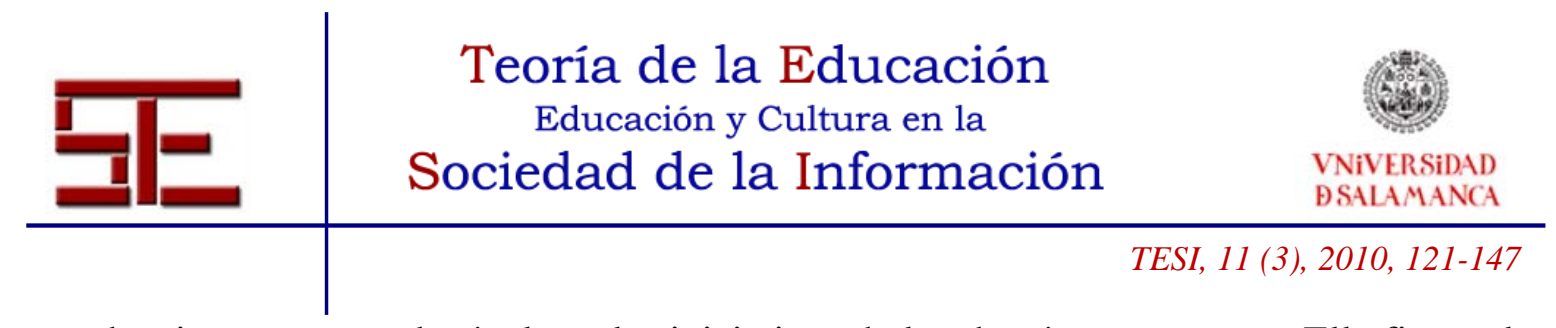

tendencia a no crear obstáculos a las iniciativas de los demás compañeros. Ella firma el proyecto TIC como firman todos los demás:

"Si, si, te aseguro que te vas a reír, bueno, cuando empezaron con el proyecto TIC, llevo en este centro 16 cursos ya, entonces pues bueno, a mí me pareció muy bien el proyecto y firmé como todo el mundo que sí. Fuimos a Cádiz, firmamos, toda la historia esa que tú ya sabes, y sabes muy bien, ...”(Párrafo 11)

Podemos decir que la variable aquí presente es la de 'implicación', aunque en esta fase inicial se manifiesta más con una escasa orientación hacia la acción, es decir, una aceptación de los posibles beneficios de iniciar el camino señalado pero no tanto la de tomar la iniciativa hacia la puesta en marcha del proyecto TIC del centro.

En la segunda fase, "tomar conciencia de las propias limitaciones: bloqueo o 'tecnofobia”,, dura aproximadamente dos años. Estos dos años se caracterizan por el miedo a 'romper' el ordenador, por la delegación de tareas domésticas familiares relacionadas con aparatos audiovisuales analógicos o digitales, pero también por la toma de iniciativas, como adquirir un ordenador aunque no lo use:

“... pero yo la verdad es que no tenía en casa ni siquiera ordenador, entonces lo primero que hice religiosamente fue comprarme un ordenador, pero yo por mi carácter tampoco tenía móvil, y además tengo 4 hijos, y yo le digo a mi hijo: -ponme el vídeo. $Y$ le daba él al vídeo, como muy negada al tema de las nuevas tecnologías, porque como no hemos aprendido eso, es cosa nueva, pues entonces yo, no me he interesado, para nada, no me ha gustado, para nada, entonces no me había preocupado, ..., y yo he ido pasándolo mal, los 2 ó 3 años primeros, lo primero que le hago al ordenador es ponerle una foto, le pongo una mesa muy bonita, y le pongo en la cabeza (en el monitor) igual del mismo color, sabía que te ibas a reír, porque yo era incapaz de coger el ratón..."(Párrafo 13)

La tercera fase la hemos llamado del "sentido de la responsabilidad". Llega un momento en que se decide a dar el paso hacia el conocimiento y uso didáctico del ordenador. Sus compañeros ya han iniciado esta andadura y se encuentran en el tercer curso académico como centro TIC. Ella se ve a sí misma como alguien que no ha cumplido con su palabra, ha firmado un compromiso que no ha asumido. Esto le hace sentirse mal y le ayuda a superar sus miedos ante las tecnologías. Toma la iniciativa de encender el ordenador y preguntar sobre su funcionamiento. Para ello utiliza tres fuentes fundamentales: a su familia, al coordinador TIC de su colegio y a sus propios compañeros de centro y de grupo de trabajo (se incorpora a un grupo de trabajo coordinado desde el Centro de Profesorado de la zona):

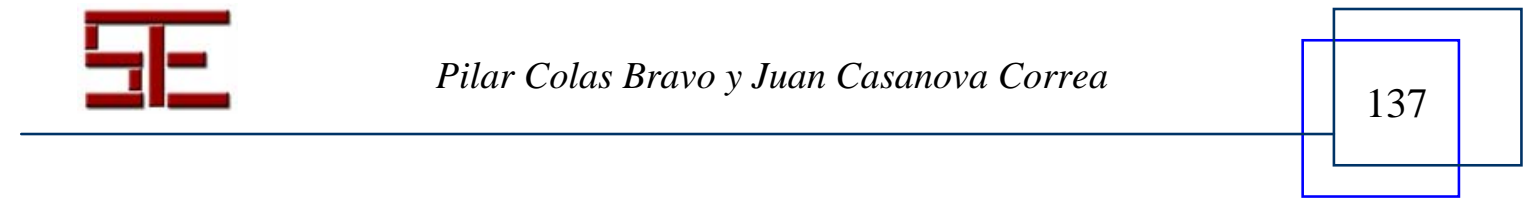




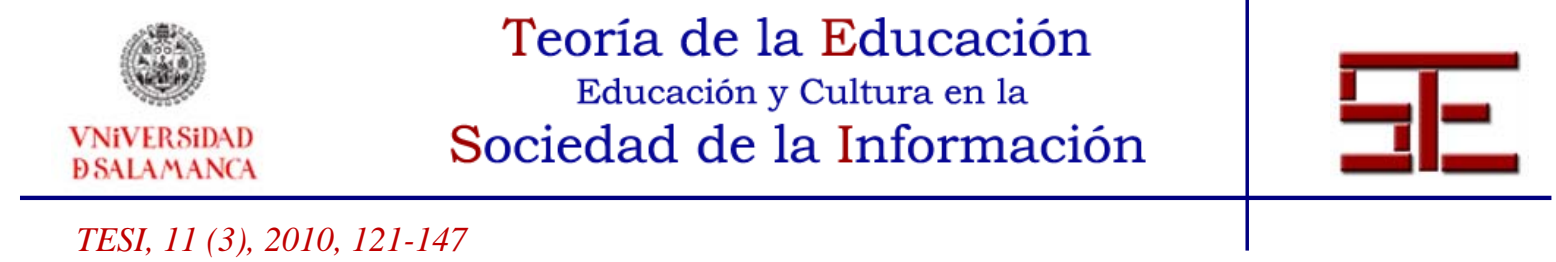

"Yo la verdad es que lo he hecho por cuestión de conciencia, yo he firmado y a mí me han educado en la responsabilidad, a mi me ha costado la misma vida, porque es algo que tú no lo reflexionas, tenía miedo porque desconocía la herramienta”(Párrafo 28).

En la cuarta fase, “acción hacia la práctica: formación y apoyo colaborativo”, se encuentra otro de los puntos de inflexión que la dirigen hacia el desarrollo de Buenas Prácticas: se anima a realizar un curso de informática centrado en el diseño de materiales didácticos usando la herramienta J-Clik. La realización de este curso le supone un gran esfuerzo personal, por el coste de tiempo extra que le tiene que dedicar, pero también le ayuda a comprender dos aspectos importantes. Por un lado, que los ordenadores no se 'rompen', por otro, que estas máquinas permiten presentar la información al alumnado de una manera más 'rica', más cercana al mundo digital que ella rechazaba y que cada vez está más presente en los hogares de sus alumnos. Por tanto, descubre una primera e importante herramienta tecnológica que puede usar en su vida docente cotidiana.

"Hace dos años, dije ¡voy a hacer un cursillo sobre los jotaclick!, por la tarde fuera de horarios y todo eso, yo no vivo aquí, vivo en Jerez y tengo una familia grande y me costó quedarme aquí hasta las 8 de la tarde. Y yo no sabía nada, porque claro hay gente que tenía una base, pero me dijeron que con el ordenador yo podía empezar por donde quisiese. Es verdad que la primera vez que yo le di al botón este, fue para empezar el curso de jotaclick, pues ahí empecé yo, al revés que todo el mundo ¿no?”(Párrafo 11)

En esta fase podemos apreciar las variables de 'Superación' y de 'Esfuerzo', y el descubrimiento de que su 'Concepción educativa' puede verse reforzado por las 'Nuevas posibilidades’ que ofrecen las TIC.

“... además que por los ojos le entra una cantidad de información..., es buenísima esta herramienta de aprendizaje, es un complemento buenísimo, además están acostumbrados a eso, a la 'tele', a la 'play', a no sé qué no se cuanto... (Párrafo 168)

En relación al grupo de trabajo, que usa como forma de 'aprender juntos', elaboran material didáctico basado en el J-Clik que comparten y mejoran. Esto lo hacen a través de las sesiones periódicas que realizan de manera presencial.

“...tenemos un grupo de trabajo..., entonces tenemos varios jotaclick hechos, lo que hacemos es poner los jotaclick como material didáctico, ahora tenemos que presentar uno, porque es sobre valores, habla sobre valores,..." (Párrafo 17)

La culminación de este proceso se alcanza en la última fase "satisfacción personal y profesional”, que se caracteriza por la valoración positiva de su propio bienestar emocional.

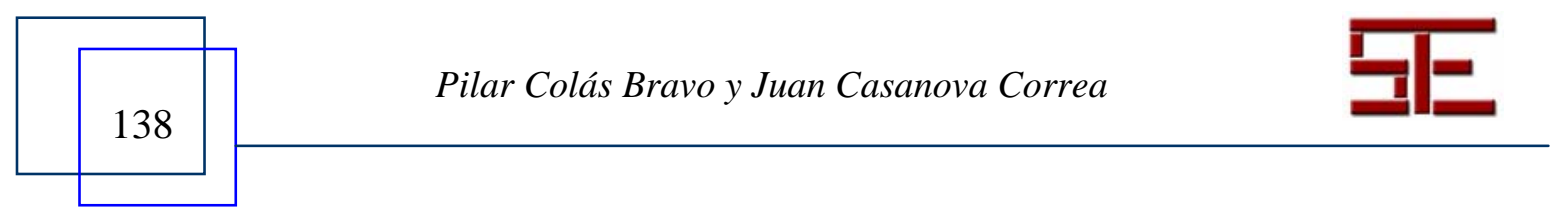




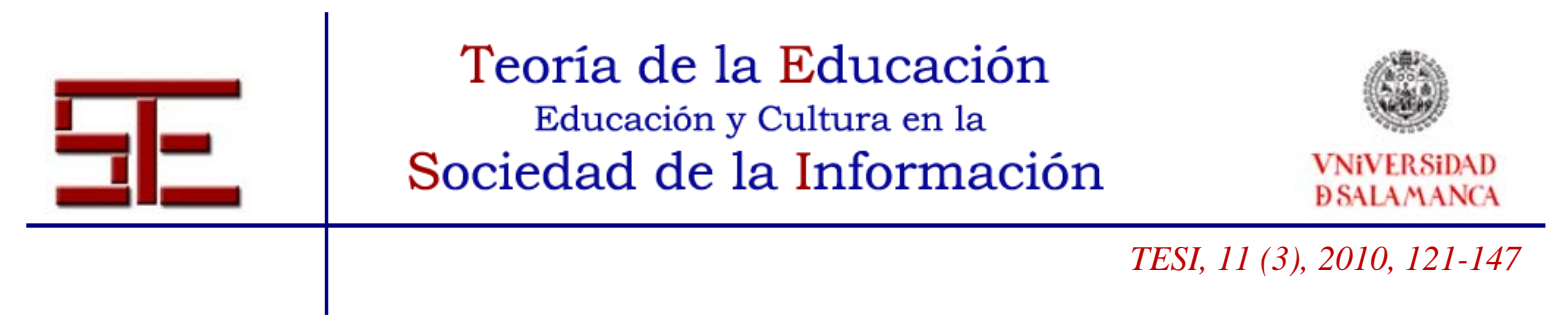

Estoy metida (en el uso de las TIC), y estoy muy contenta, pues sí, la verdad es que sí. (Párrafo 7)

“...entonces para mí ha sido una ventana que se me ha abierto y estoy muy contenta, yo con esto me divierto con ellos”. (Párrafo 38)

Lo comentado hasta ahora ha pretendido explicar el proceso seguido de esta maestra de primaria en el desarrollo de Buenas prácticas con TIC, relacionándolo con las variables que hemos identificado y que la justifican. Hemos indicado anteriormente el carácter cíclico del final de ese proceso. Pasemos a comentarlo.

Cuando definimos el final del proceso como cíclico queremos resaltar cómo se ha creado un círculo formado por cuatro variables que en la actualidad se encuentra en una situación de retroalimentación positiva que posibilitan un refuerzo permanente de cada una de ellas para la generación de Buenas Prácticas con TIC. Estas cuatro variables serían: Implicación, Profesorado (que es una variable que aparecerá en la dimensión contextual que comentamos a continuación), Concepción educativa y Satisfacción. En la Figura 4 intentamos reflejar esta idea.

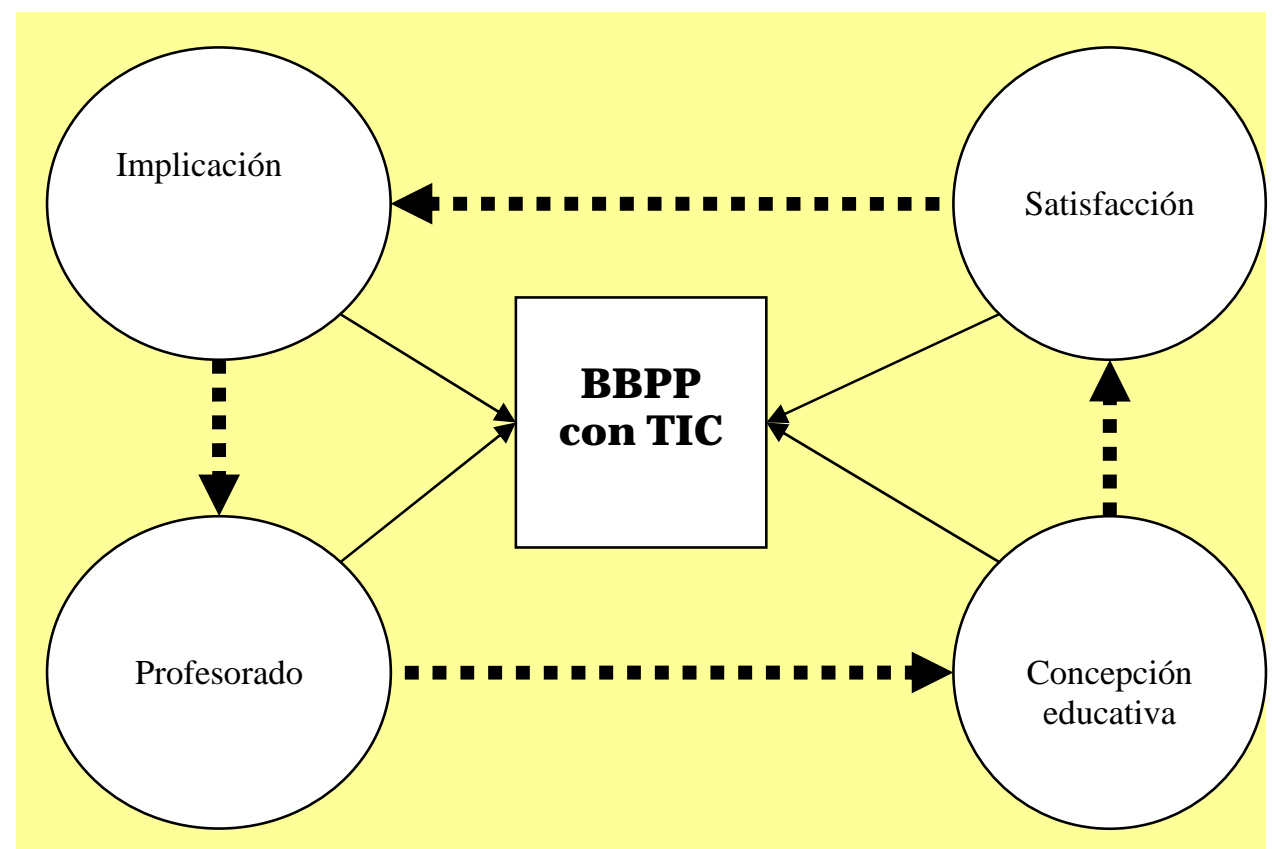

Figura 4. Factores condicionantes de las BBPP con TIC en la fase final del proceso.

Hasta aquí hemos intentado explicar, en este caso, la dimensión personal que justificaría el desarrollo de Buenas Prácticas con TIC Pasemos ahora a comentar la

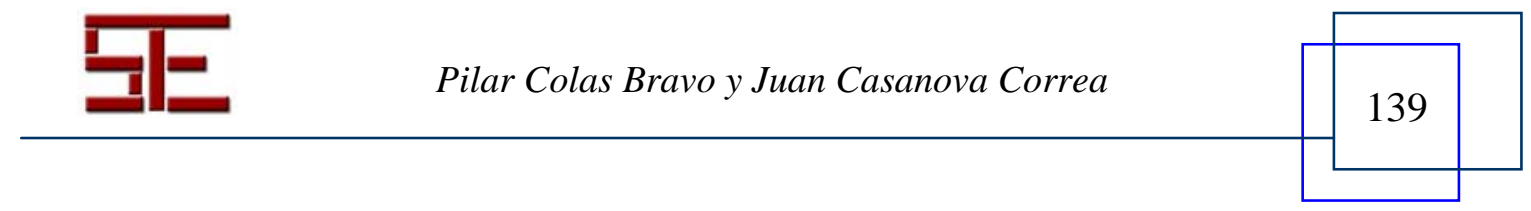




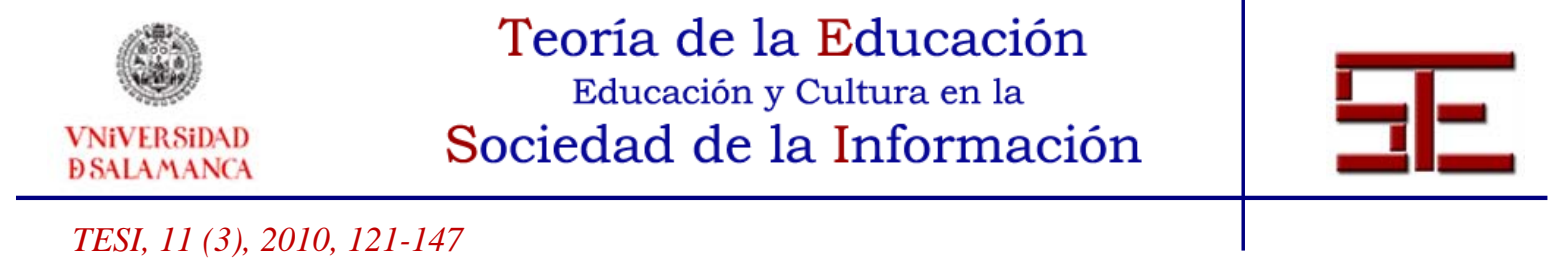

dimensión contextual, ya señalada en la figura 2 como aquella que interactúa con la dimensión personal para el desarrollo de BBPP.

\section{2.- Factores de índole contextual asociados a las buenas prácticas.}

El análisis inductivo de los datos nos devela las siguientes variables relacionadas con aspectos de índole contextual (ver Tabla 2).

\begin{tabular}{|c|c|c|}
\hline Variables contextuales & Concepto & Episodio Narrativo \\
\hline Política Autonómica & $\begin{array}{l}\text { Conjunto de iniciativas legislativas y } \\
\text { normativas que favorecen la } \\
\text { integración de las TIC en los centros } \\
\text { educativos }\end{array}$ & $\begin{array}{l}\text { “...cuando empezaron con el proyecto } \\
\text { TIC...Fuimos a Cádiz, firmamos.” }\end{array}$ \\
\hline Profesorado & $\begin{array}{l}\text { Tareas de asesoramiento, apoyo y } \\
\text { colaboración generadas en grupo y } \\
\text { dirigidas al uso de las TIC }\end{array}$ & $\begin{array}{l}\text { “...tenemos un grupo de trabajo..., } \\
\text { entonces tenemos varios J-click hechos, } \\
\text { lo que hacemos es poner los J-click } \\
\text { como material didáctico...” }\end{array}$ \\
\hline Coordinador TIC & $\begin{array}{l}\text { Actividades desarrolladas por el } \\
\text { coordinador TIC del centro que } \\
\text { permiten al conjunto de la } \\
\text { comunidad educativa conocer y usar } \\
\text { de manera más efectiva a las TIC }\end{array}$ & $\begin{array}{l}\text { "Si Cristóbal me ha hecho ahora... una } \\
\text { carpeta, un directorio particular ¿no? } \\
\text { Donde yo entro con mi clave y lo puedo } \\
\text { abrir de un lado en otro, en otro y en } \\
\text { otro, no solo aquí." }\end{array}$ \\
\hline Experiencias previas & $\begin{array}{l}\text { Conjunto de conocimientos, } \\
\text { habilidades y actitudes de la } \\
\text { profesora antes de comenzar a usar } \\
\text { las TIC en el aula ordinaria }\end{array}$ & $\begin{array}{l}\text { “...yo no sabía nada, porque claro hay } \\
\text { gente que tenía una base, pero me } \\
\text { dijeron que con el ordenador yo podía } \\
\text { empezar por donde quisiese,...” }\end{array}$ \\
\hline Contexto familiar & $\begin{array}{l}\text { Nivel de alfabetización del contexto } \\
\text { familiar del alumnado }\end{array}$ & $\begin{array}{l}\text { "Esto lo han hecho aquí se lo han llevado } \\
\text { en la bellota y lo han impreso en } \\
\text { casa,..." }\end{array}$ \\
\hline Familia propia & $\begin{array}{l}\text { Apoyo recibido por parte de la } \\
\text { familia para poder conocer y usar } \\
\text { recursos tecnológicos }\end{array}$ & $\begin{array}{l}\text { “... el otro día le digo a mi hijo, escucha } \\
\text { siéntate aquí, dime como se hace } \\
\text { esto,...” }\end{array}$ \\
\hline Buena Práctica & $\begin{array}{l}\text { Conjunto de actividades realizadas } \\
\text { con TIC que mejoran los procesos de } \\
\text { enseñanza-aprendizaje, } \\
\begin{array}{l}\text { colaboración en el centro o las } \\
\text { relaciones entre los actores } \\
\text { educativos }\end{array}\end{array}$ & $\begin{array}{l}\text { “... los que no trabajan normalmente son } \\
\text { los que les encanta (hacer) los trabajos, } \\
\text { les encanta el ordenador y te lo mandan } \\
\text { (por correo electrónico) ...lo ha hecho, } \\
\text { ha pegado sus cositas sus fotos y me lo } \\
\text { ha mandado a mi correo entonces yo lo } \\
\text { evalúo...” }\end{array}$ \\
\hline
\end{tabular}

Tabla 2.

Estas variables están relacionadas entre sí, como recogemos en la Figura 5.

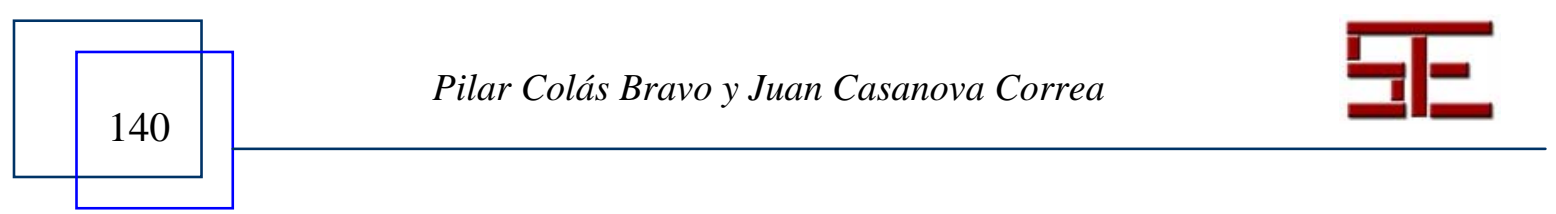



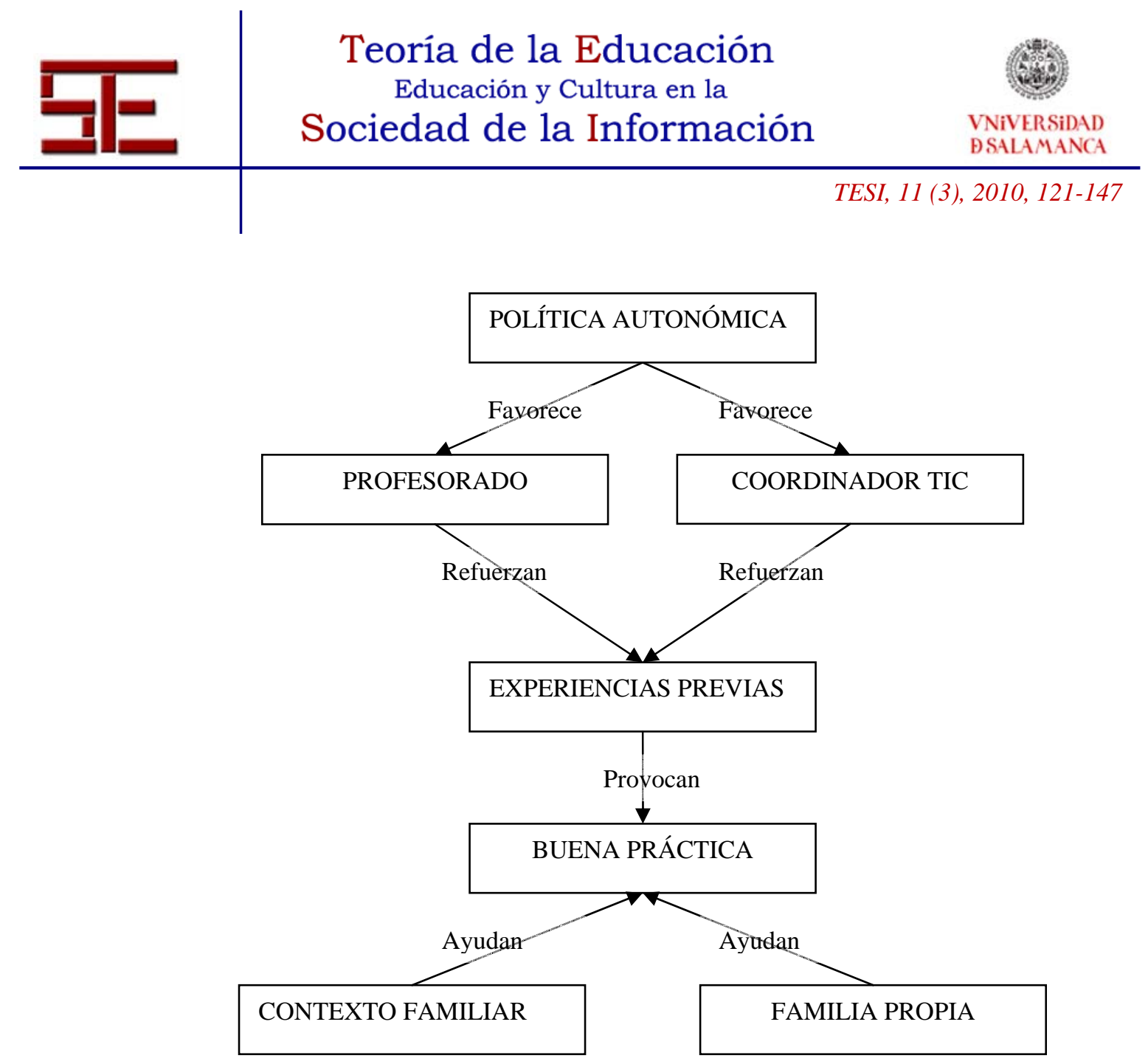

Figura 5. Relaciones observadas entre las variables contextuales

Podemos decir que nos encontramos ante un caso de falta de formación digital ('Experiencia previa') por una cuestión generacional, del momento tecnológico que le tocó vivir en su infancia y adolescencia.

“...como muy negada al tema de las nuevas tecnologías, porque como no hemos aprendido eso, es cosa nueva, pues entonces a mí no me ha interesado, para nada, no me ha gustado, para nada, entonces no me había preocupado". (Párrafo 11)

El contexto que la ha rodeado ha favorecido su iniciación en estas herramientas y su incorporación en los procesos de enseñanza/aprendizaje. Este contexto tiene varios puntos de referencia que pueden hacernos entender cómo se ha podido favorecer el desarrollo de Buenas Prácticas. Ya hemos indicado que se pueden identificar tres niveles de implantación: Introducción, Aplicación e Integración, y en el caso que nos ocupa, así lo hemos detectado. El nivel de ‘Introducción’ lo podemos identificar con los

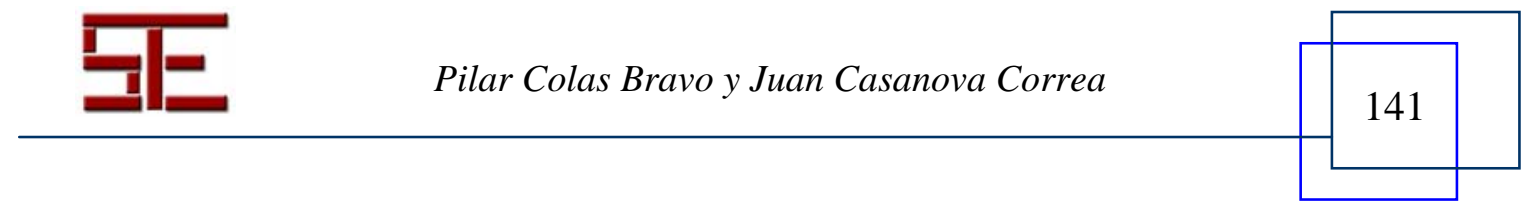




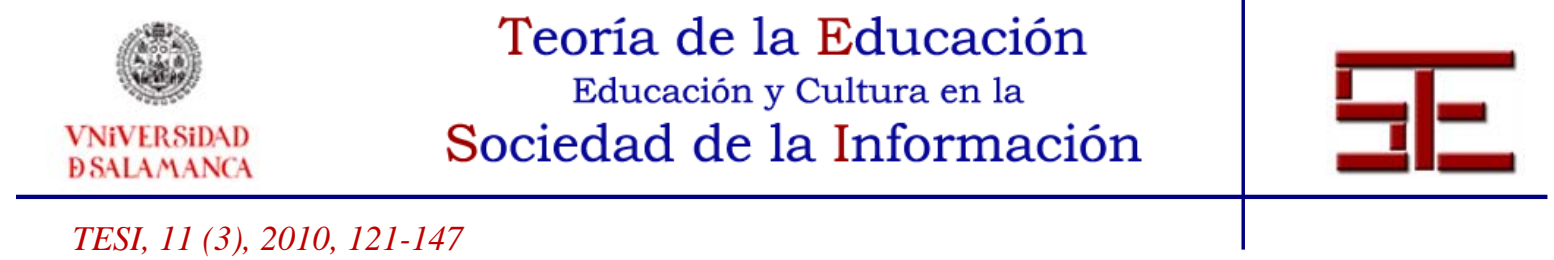

primeros momentos de diseño del proyecto TIC, de debate en el seno del centro sobre su pertinencia o no, de la decisión final de asumir el compromiso, y, por último, la dotación de los recursos tecnológicos necesarios.

Podemos considerar que el centro educativo en cuestión se encuentra en un momento intermedio entre la fase de ‘Aplicación’ y la fase de 'Integración'. Nos vamos a centrar exclusivamente en los aspectos didácticos/pedagógicos y no tanto en los formales/organizativos, que en el nivel de 'Integración' deben estar presentes y, además, lo vamos a analizar en función del caso de la profesora que nos ocupa.

La primera variable de una gran influencia es la de la 'Política Autonómica', sobre todo, porque forma parte del conjunto de decisiones que los responsables de la implantación de las TIC en Andalucía han tomado durante los últimos años. Pero hay otras dos variables contextuales, que han sido favorecidas por la política autonómica, y que permitirán ir reforzando las experiencias previas con TIC para poder adquirir las competencias necesarias para su uso. Para la entrevistada, el éxito en el uso de las TIC ha dependido tanto de variables 'esperadas' como 'casuales'. Entre las variables 'esperadas' nos encontraríamos con:

- Profesorado (con el que forma un grupo de trabajo)

- El coordinador TIC de su centro

Entre las variables más ‘casuales’ o fortuitas estarían:

- Familia propia (con hijos adolescentes que usan TIC en el hogar)

- Contexto familiar (referido al alumnado que en su mayoría tiene ordenador y conexión a Internet en el hogar)

Así, si tomamos en consideración las variables personales comentadas en el punto anterior con la confluencia de los factores contextuales indicados, se puede comprender la rápida iniciación e incorporación de las TIC al quehacer docente. El papel jugado por el coordinador TIC del centro es un factor decisivo. Por un lado, incorpora las iniciativas planteadas desde la administración o desde el centro de profesorado que coordina a todos los centros TIC de la zona; pero, por otro lado, sirve de asesor técnico y pedagógico de todos los implicados del centro y asume tareas de formación tanto del profesorado como del alumnado.

"Ahora, yo no le he enseñado a ellos a hacer presentaciones, se las ha enseñado Cristóbal (coordinador TIC del centro), yo recojo el trabajo de él." (Párrafo 106)

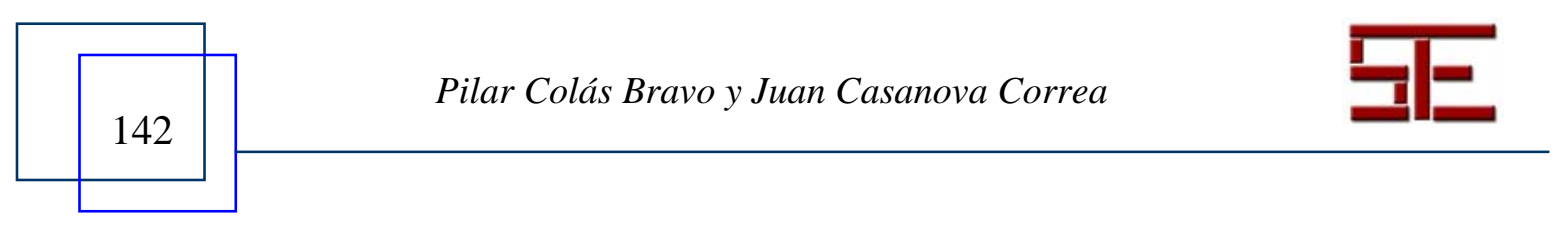




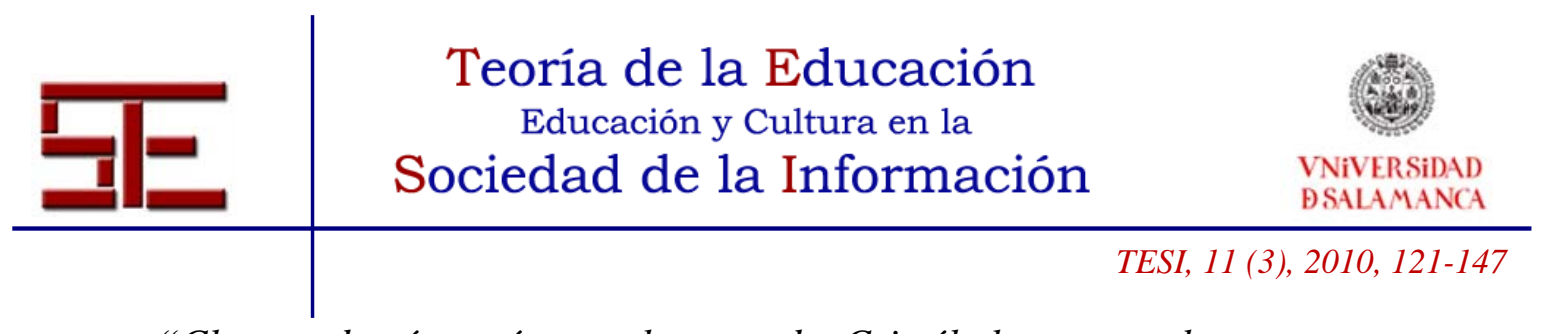

"Claro, además a mí no me ha entrado, Cristóbal entra con los tutores y se queda el tutor y les enseña a los niños la herramienta," (Párrafo 108)

Si, Cristóbal me ha hecho ahora un... ¿cómo se dice?...Si eso una carpeta, un directorio particular ¿no? donde yo entro con mi clave y lo puedo abrir de un lado en otro, en otro y en otro, no solo aquí (en un ordenador concreto), que tenía que ir antes con la bellota (se refiere al lápiz de memoria) para todos lados," (Párrafo 92)

Por otro lado, los compañeros de trabajo, ya sean de su área o del propio centro, han supuesto el colectivo con el que compartir sus dificultades técnicas y sus planteamientos didácticos. Pero, como ya hemos comentado, esto no hubiera sucedido si no hubiera confluido con una de sus características personales: capacidad para realizar esfuerzos añadidos.

"Claro, eso quieren este año, ponerlo disponible para todas las personas que lo quieran utilizar (ponerlo a disposición en Internet), es más algunos compañeros han preguntado y, no lo sé si para el año que viene, lo haré o no lo haré, la verdad, todavía no lo tengo muy claro, pero han pedido que les pongamos el trabajo que estamos haciendo de J-click, porque, claro, esto de las nuevas tecnologías es muy llamativo, $y$ es verdad que los J-click son muy atractivos para los niños”.(Párrafo 19)

De entre las variables más 'casuales' o fortuitas, se encuentra el que esta profesora tenga 4 hijos que usan las tecnologías del hogar y las de la comunicación con un nivel de dominio muy superior al de su madre, y no duda en solicitar su asesoramiento.

“...y lo último ya que estoy haciendo son unas presentaciones, que eso he empezado hace dos semanas, que bueno yo no había hecho nunca presentaciones, pero el otro día le digo a mi hijo, escucha siéntate aquí, dime cómo se hace esto. Tú sabes los niños, los adolescentes estos me dicen: - mamá, tú nunca vas a aprender, porque es que tu.. iqué haces apuntando!... Chiquillo porque después no me acuerdo. Porque claro como ellos se entienden estupendamente, pues entonces mamá es la torpe de la casa, pero la verdad es que no tiene dificultad el Power Point”. (Párrafo 15)

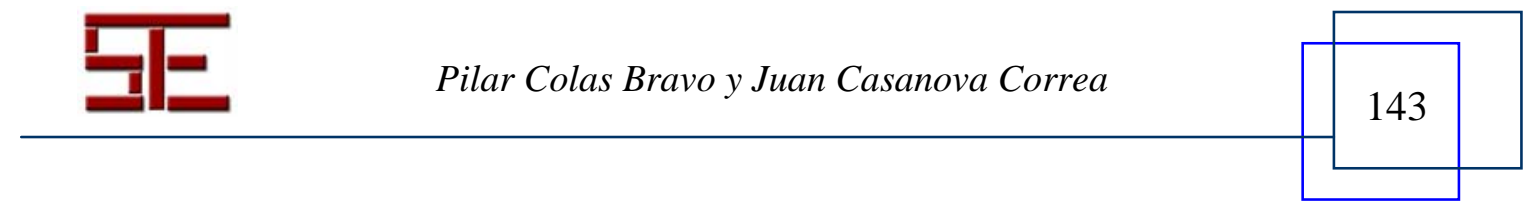




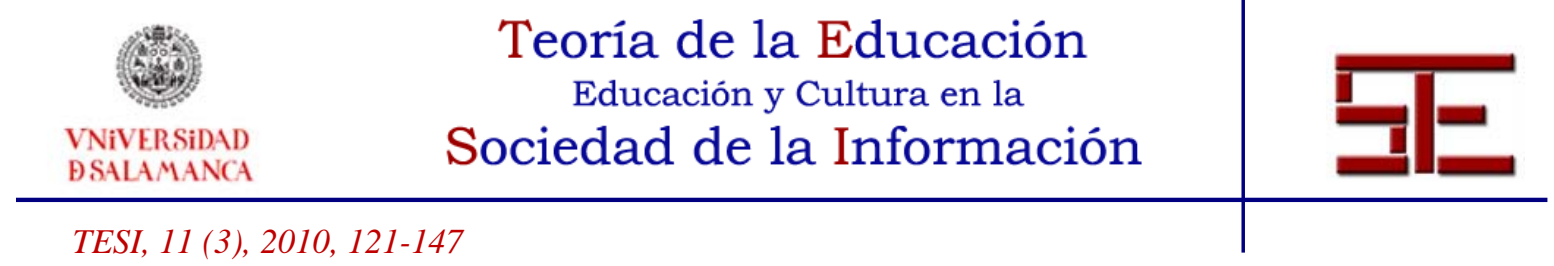

El segundo factor 'casual' que ha intervenido tiene mucho que ver con la ubicación del centro: en un barrio de clase media trabajadora, con suficientes recursos para tener un ordenador en casa y una conexión a Internet. Esto supone que las tareas a realizar pueden seguir siendo 'digitales', utilizando el ordenador. Además implica una mayor autonomía del alumnado y la posibilidad de realizar mayores avances en el aprendizaje.

“...o sea, yo sé que ellos se meten en la plataforma, van a la guía didáctica y van a los 5 bloques de contenidos que tienen. No tienen para irse, ellos trabajan con los bloques, trabajan por unidades, y vamos pasando, pasando, pasando...Luego, por otro lado, me mandan trabajos que yo les mando, ¿no? Muchos me lo traen impreso, y otros que no tienen impresora en casa y aquí hay ordenadores pues por las tardes vienen y me lo mandan por correo, entonces yo se los corrijo por correo electrónico." (Párrafo 15)

\section{6.- CONCLUSIONES}

En el caso que nos ocupa, hemos identificado una serie de variables que nos han ayudado a comprender el proceso seguido por una profesora de un centro de primaria en su incorporación al mundo digital aplicado a la educación y cómo esta aplicación ha supuesto unos cambios importantes a nivel de innovación en su quehacer profesional cotidiano. Hemos identificado dos dimensiones diferenciadas de variables: la personal y la contextual. Respecto a la primera es importante destacar que nos encontramos ante una profesional de amplia experiencia (16 años) con una inexperiencia e incluso 'fobia' a todo aquello que tenga una base tecnológica (analógica o digital), pero con un gran sentido de la responsabilidad. Asumir su responsabilidad docente conlleva no sólo el responder a su alumnado, sino también asumir los retos que se le plantean desde la administración pública y desde su propio grupo de compañeros de centro. La clave en este caso, desde la dimensión personal, hay que buscarla en la combinación de una actitud responsable con una capacidad para asumir retos.

Pero, ¿y en relación a la dimensión contextual? El contexto próximo ha sido también decisivo. Por un lado, el papel jugado por el coordinador TIC, asumiendo tareas de asesor técnico, organizador de actividades formativas para el alumnado y para el profesorado... ha supuesto la constatación de un liderazgo en el centro. Por otro lado, no debemos olvidar que la administración educativa es la que ha diseñado el marco de acción. A través, primero, de la exigencia de un compromiso materializado en un proyecto TIC para el centro y, segundo, facilitando la organización del profesorado a través de los grupos de trabajo. Esta organización ha permitido que nuestra maestra pueda iniciar un proceso formativo y de acción sobre su práctica docente.

Ambas dimensiones, la personal y la contextual, se han visto reforzadas, se han complementado, y han permitido que se produzca la percepción de satisfacción por el

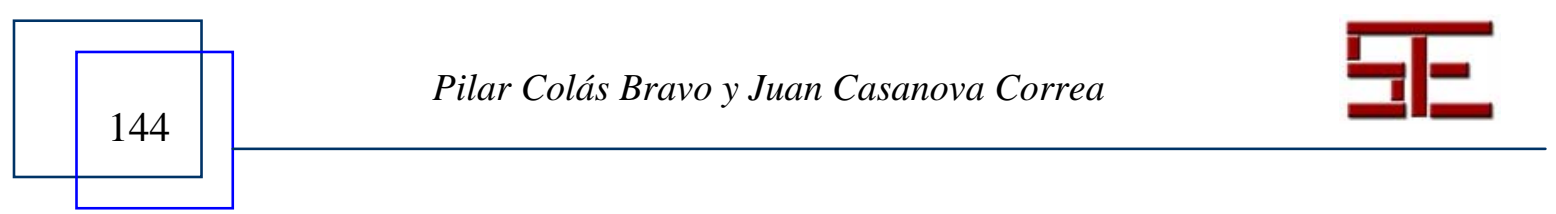




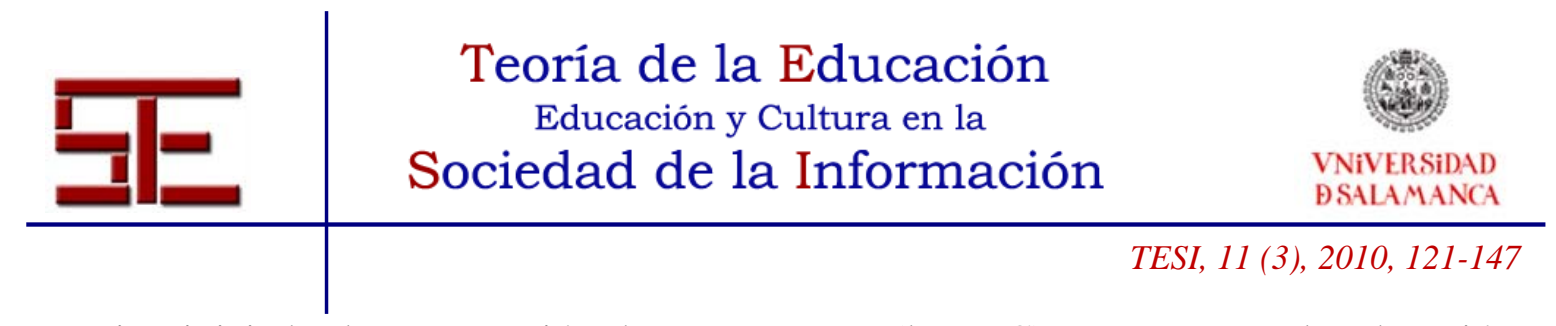

camino iniciado, la constatación de que suponen (las TIC) un avance en la educación por sus cualidades motivadoras y de mejora de los aprendizajes, y la convicción de que no hay vuelta atrás: ya no concibe una enseñanza sin que se apoye en las TIC.

\section{7.- BIBLIOGRAFÍA}

Colás, P. (2001/2002). Evaluación de la implantación de tecnologías de la información y la comunicación en centros escolares. Qurriculum: Revista de teoría, investigación y práctica educativa, $\mathrm{n}^{\circ} 15,91-115$.

De Pablos, J. (2000). Los centros de profesorado y su incidencia en la implantación de las nuevas tecnologías en el sistema educativo andaluz. En M. Lorenzo, M.D. García, J.A. Torres, J.A. Ortega, S. Debón \& A. Notoria (eds.). Las organizaciones educativas en la sociedad neoliberal (vol. I). Granada: Grupo Editorial Universitario. Universidad de Granada.

De Pablos, J. Y Colás, P. (Dir.) (1998). La implantación de las Nuevas Tecnologías de la Información y la Comunicación en el Sistema Educativo Andaluz: un estudio evaluativo. Grupo de Investigación, Evaluación y Tecnología Educativa. (Universidad de Sevilla) (Investigación inédita)

De Pablos, J. Y González, T. (2007). Políticas educativas e innovación educativa apoyada en TIC; sus desarrollos en el ámbito autonómico. Comunicación publicada en las Actas de las II Jornadas Internacionales sobre políticas educativas para la sociedad del conocimiento. Granada.

Ertmer, P. (2005). Teacher pedagogical beliefs: the final frontier in our quest for technology integration? Educational Development Research and Development, 53, 25-39.

Fullan, M. (2001). The New Meaning of Educational Change, 3rd edition. New York: Teachers College, Columbia University.

Gobbo, C. \& Girardi, M. (2001). Teachers' beliefs and integration of information and communications technology in in Italian schools. Journal of Information Technology for Teacher Education, 10 (1/2), 63-86

Hennessy, S., Ruthven, K. \& Brindley, S. (2005). Teacher perspectives on integrating ICT into subject teaching: commitment, constrains, caution, and change. Journal of Curriculum Studies, 37, 155-192.

Karagiorgi, y Charalambous, K. (2004). Curricula Considerations in ICT Integration: Models and Practices in Cyprus. Education and Information Technologies, 9:1, 21-35

Kim, Y. (2000). Teachers attitudes towards computers: a primary factor affecting computer uptake in the classroom. Unpublished thesis, Kings College, London.

Kinsler, K. \& Gamble, M. (2002). Reforming Schools. New York: Continuum.

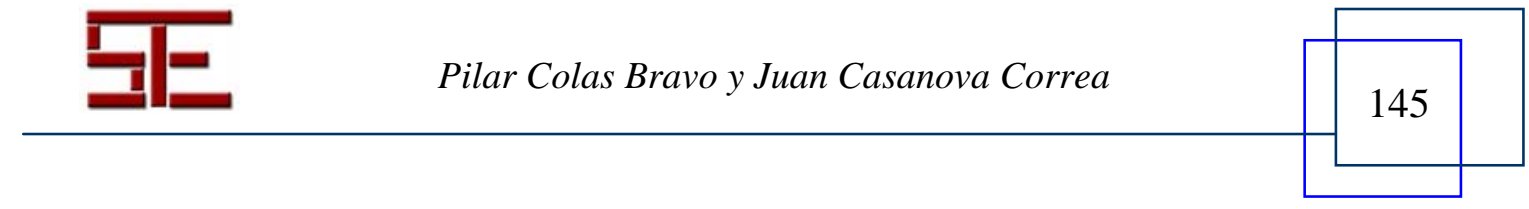




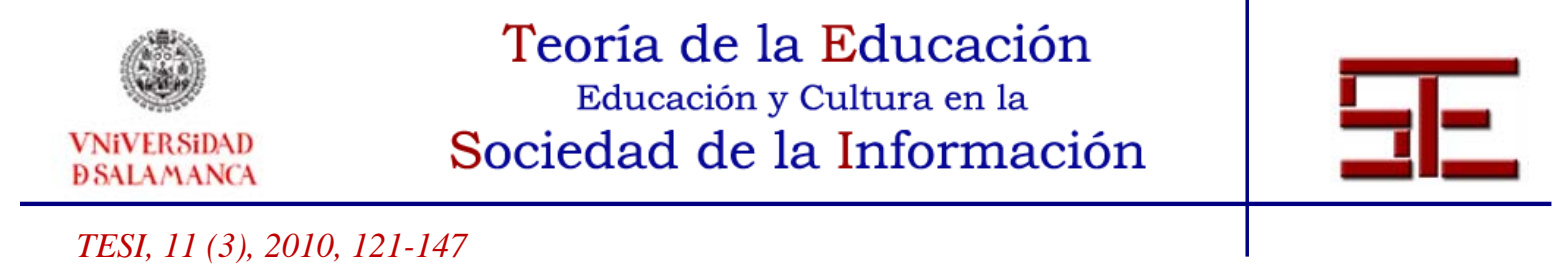

Kozma R. (ed.) (2003). Technology, Innovation and Educational Change: A Global Perspective. OR: Information Society for Technology in Education [ISTE] Publications. Eugene.

Landow, G. (2004). Innovación educativa e hipertexto. Éxitos y fracasos de una universidad en apoyo de la nueva tecnología. En I. Snyder (comp.) (pp. 149170). Alfabetismos digitales, Málaga: Ed. Aljibe.

Loveless, A. (2003). The Interaction Between Primary Teachers' Perceptions of ICT and Their Pedagogy. Education and Information Technologies, 8:4, 313326.

Loveless, A. \& Dore, B. (eds.) (2002). ICT in the primary school. Learning and teaching with ICT. Buckingham, UK: Open University Press.

Meelissen, M. (2005). ICT: meer voor Wim dan voor Jet? De rol van het basisonderwijs in het aantrekkelijker maken van ICT voor jongens en meisjes. Enschede, the Netherlands. PrintPartners.

Mioduser, D., Nachmias, R., Tubin, D. \& Forkosh-Baruch, A. (2003). Analysis schema for the study of domains and levels of pedagogical innovation in schools using ICT. Education and Information Technologies, 8(1), 23- 36.

Nachmias, R. et al. (2004). Factors Involved in the Implementation of Pedagogical Innovations Using Technology. Education and Information Technologies, 9:3, 291-308.

Niederhauser D. \& Stoddart T. (2001). Teachers' instructional perspectives and use of educational software. Teaching and Teacher Education 17, 15-31.

Song, L., Hannafin, M. \& Hill, J. (2007). Reconciling beliefs and practices in teaching and learning. Educational Technology Research and Development, 55, 27-50.

Tearle, P. (2003). ICT implementation: what makes the difference? British Journal of Educational Technology vol, $34 N^{\circ}$ 5, 567-583.

Tondeur, J. Valcke, M. \& Van Braak, J. (2008). A multidimensional approach to determinants of computer use in primary education: teacher and school characteristics. Journal of Computer Assisted Learning, 24, 494-506.

Tondeur, J., Van Braak, J \& Valcke, M. (2007). Curricula and the use of CT in education: Two worlds apart. British Journal of Educational Technology, vol 38 $N^{\circ}$ 6, 962-976.

Van Braak, J. (2001). Factors influencing the use of computers mediated communication by teachers in secondary education. Computers and Education, 36, 41-57.

Venezky, R. \& Dais, C. (2001). Que Vademus? The Transformation of Schooling in a Networked World. OECD/CERI. URL: http://www.oecd.org/findDocument/0,2350,en_2649_33723_1_119832_1_1_1,0 $0 . h t m l$

Zhao, Y. \& Frank, K. A. (2003). Factors affecting technology uses in schools: an ecological perspective. American Educational Research Journal, 40, 4, 807-940.

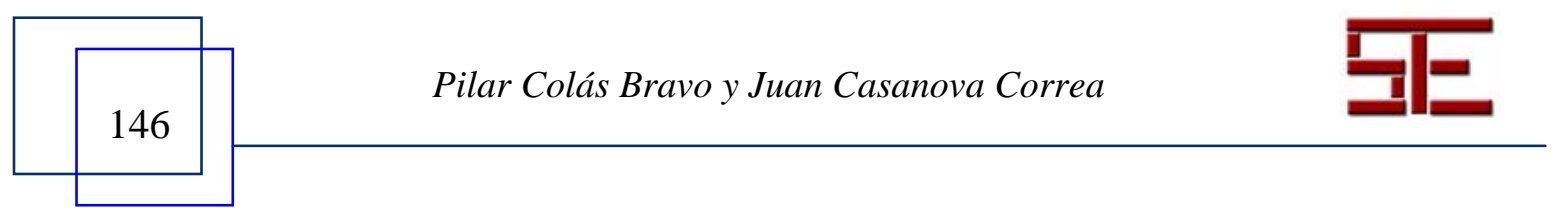




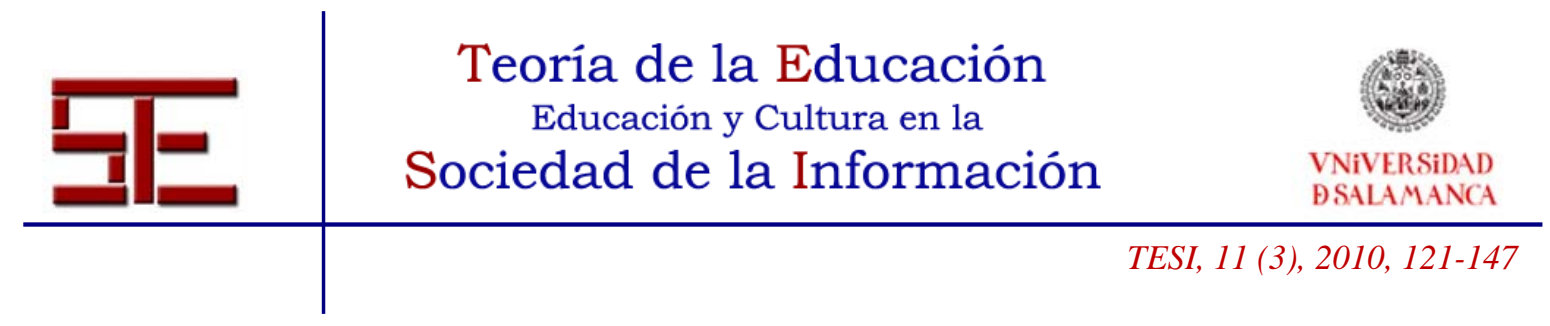

Para citar el presente artículo puede utilizar la siguiente referencia:

Colas Bravo, P. y Casanova Correa, J.: (2010). "Variables docentes y de centro que generan buenas prácticas con TIC”. En De Pablos Pons, J. (Coord.) Buenas prácticas de enseñanza con TIC [monográfico en línea]. Revista Electrónica Teoría de la Educación: Educación y Cultura en la Sociedad de la Información. Vol. 11, n ${ }^{\circ} 1$. Universidad de Salamanca, pp. 121-147. [Fecha de consulta: dd/mm/aaaa].

http://revistatesi.usal.es/ revistas_trabajo/index.php/revistatesi/article/view/5791/5863 ISSN: 1138-9737

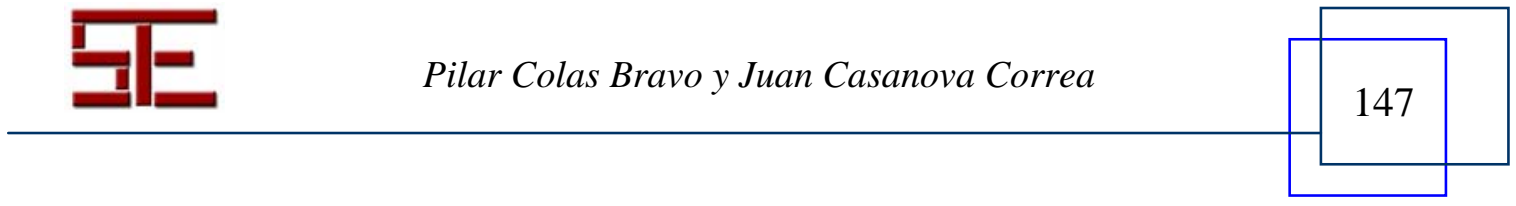

